Florida International University FIU Digital Commons

\title{
Group conflict handling: effects on group conflict type-group outcome relationships
}

Leslie A. DeChurch

Florida International University

DOI: $10.25148 /$ etd.FI14062230

Follow this and additional works at: https://digitalcommons.fiu.edu/etd

Part of the Psychology Commons

\section{Recommended Citation}

DeChurch, Leslie A., "Group conflict handling: effects on group conflict type-group outcome relationships" (2000). FIU Electronic Theses and Dissertations. 2760.

https://digitalcommons.fiu.edu/etd/2760

This work is brought to you for free and open access by the University Graduate School at FIU Digital Commons. It has been accepted for inclusion in FIU Electronic Theses and Dissertations by an authorized administrator of FIU Digital Commons. For more information, please contact dcc@fiu.edu. 


\title{
FLORIDA INTERNATIONAL UNIVERSITY
}

Miami, Florida

\section{GROUP CONFLICT HANDLING:}

\section{EFFECTS ON GROUP CONFLICT TYPE-GROUP OUTCOME RELATIONSHIPS}

\author{
A thesis submitted in partial fulfillment of the \\ requirements for the degree of \\ MASTER OF SCIENCE \\ in \\ PSYCHOLOGY \\ by \\ Leslie A. DeChurch
}


To: Dean Arthur W. Herriott

College of Arts and Sciences

This thesis, written by Leslie A. DeChurch, and entitled Group Conflict Handling: Effects on Group Conflict Type-Group Outcome Relationships, having been approved in respect to style and intellectual content, is referred to you for judgment.

We have read this thesis and recommend that it be approved.

Juan I. Sanchez

Chockalingam Viswesvaran

Michelle A. Marks, Major Professor

Date of Defense: March 20, 2000

The thesis of Leslie A. DeChurch is approved.

Dean Arthur W. Herriott College of Arts and Sciences

Dean Richard L. Campbell Division of Graduate Studies

Florida International University, 2000 


\section{DEDICATION}

I dedicate this thesis and all the hard work that went into it to the two people whose

guidance, love, and support have made my educational endeavors possible, my husband Jeff, and my mom. 


\section{ACKNOWLEDGMENTS}

I sincerely thank my committee members, Dr. Juan I. Sanchez and Dr.

Chockalingam Viswesvaran for all of their advice and wisdom throughout this process. I'm especially grateful to my Major Professor, Dr. Michelle Marks. In addition to all of her wonderful ideas and suggestions, her sincere patience, understanding, and optimism are a source of unending motivation.

I am very grateful to Kimberly Taylor, Sherry Moss, Earnest Friday, Michael Munro, and Stephanie Castro for their participation and assistance with data collection. Had their students not engaged in conflict, this study truly wouldn't have been possible.

I would also like to thank some other faculty members in the field that have significantly influenced my development as a doctoral student and as a person. My heartfelt thanks and appreciation are with Maurice Schweitzer for his guidance, especially in the domain of conflict study. I am also very grateful for the mentoring and methods training of Chester Schriesheim.

I must also thank all of my fellow graduate students who've contributed to this work in somewhat less formal ways, by making this process (so far) survivable and even enjoyable. Thanks especially to Stephanie Castro, Ethlyn Williams, Amy Cooper, and Fred Panzer. And Lastly, I am extremely grateful for the encouragement of my entire family. My brother, grandparents, and mother- and father-in-law, in particular, have been a tremendous source of strength and support throughout. 


\section{ABSTRACT OF THE THESIS \\ GROUP CONFLICT HANDLING:}

EFFECTS ON GROUP CONFLICT TYPE-GROUP OUTCOME RELATIONSHIPS

by

Leslie A. DeChurch

Florida International University, 2000

Miami, Florida

Professor Michelle A. Marks, Major Professor

Intragroup conflict research has shown task and relationship conflict have different effects on group outcomes, and suggests groups promote task conflict while avoiding relationship conflict. However, these suggestions have not yet been tested. This study examines the moderating role of group conflict handling on conflict type-group outcome relationships. Results of a field survey of 96 business school project groups showed task conflict inhibited performance when groups used avoidance tactics; however, these effects were negated when avoidance tactics were not used. Similarly, relationship conflict was only harmful to performance when avoided. When the use of avoidance was low, relationship conflict improved performance. Collaboration mitigated the harmful effects of task conflict and compromising mitigated those of relationship conflict on group satisfaction. Results from this work provide an important first look at how group conflict handling behaviors moderate the relationships between conflict types and group outcomes. 


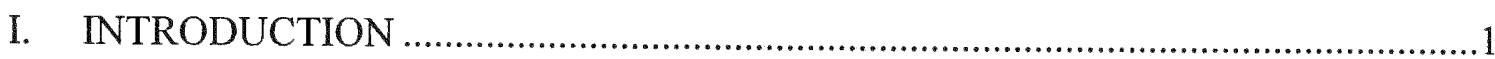

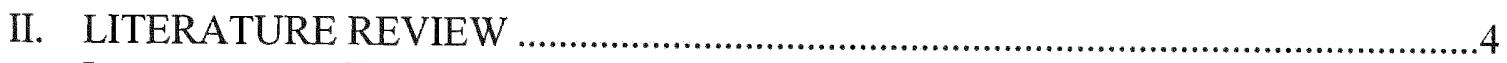

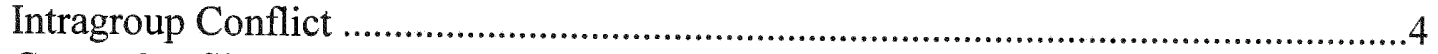

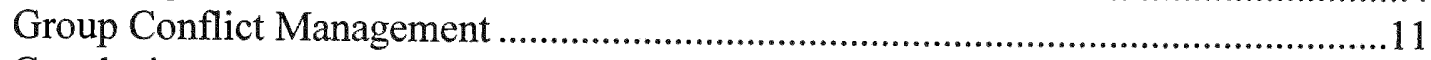

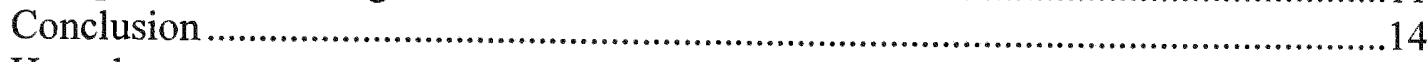

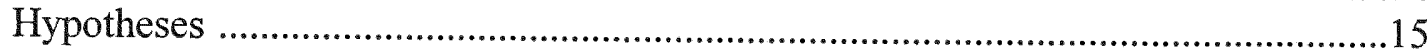

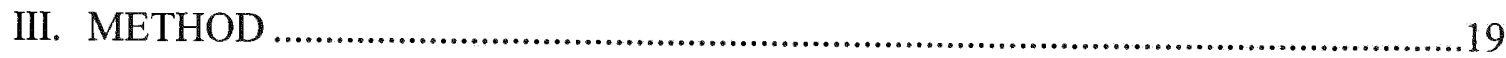

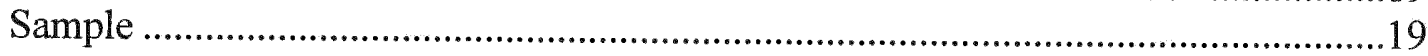

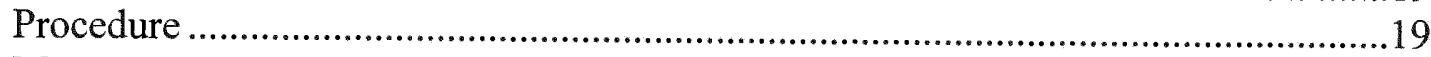

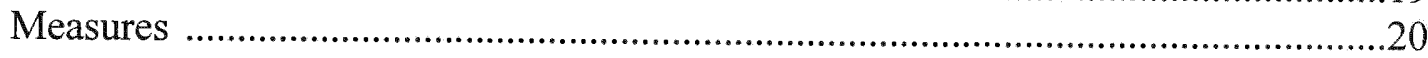

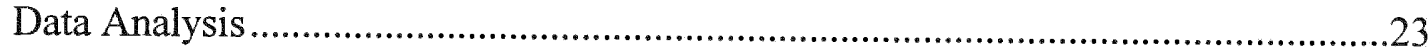

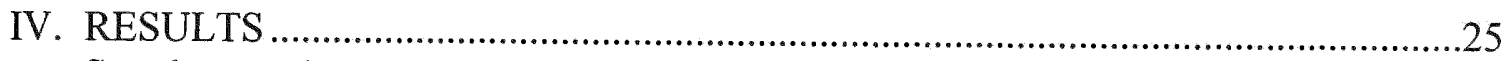

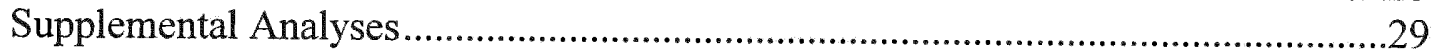

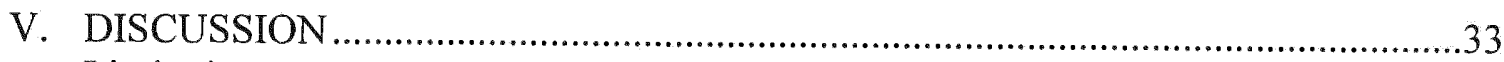

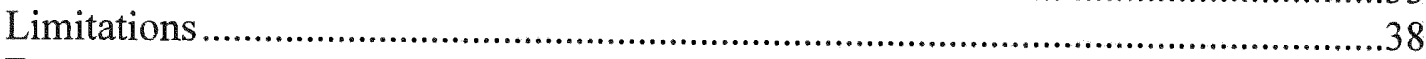

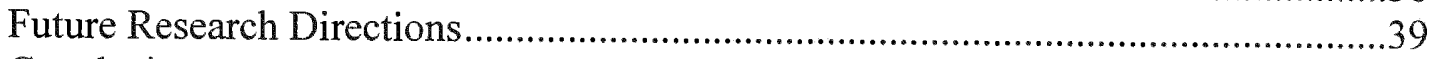

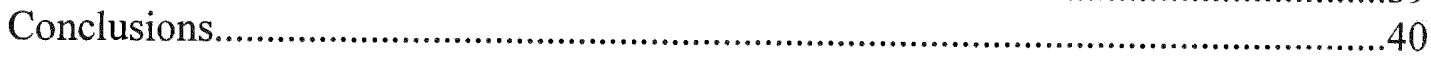

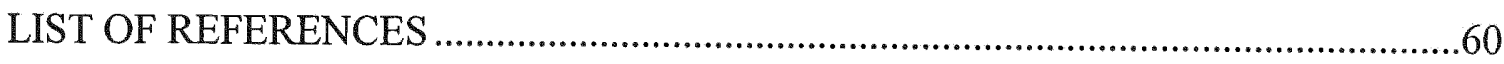

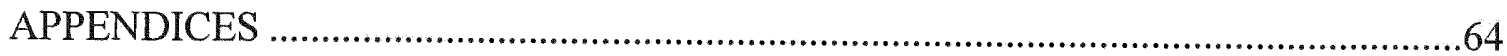




\section{LIST OF TABLES}

TABLE

PAGE

1. Individual-Level Variable Means, Standard Deviations, and Coefficient Alpha Reliabilities $(\mathrm{N}=391)$. 41

2. Median Within-Group Agreement (rwg(j)) Coefficients and Group-Level Variable Means, Standard Deviations, and Intercorrelations for Task Conflict and Task Conflict Handling $(\mathrm{N}=96)$

3. Median Within-Group Agreement (rwg(j)) Coefficients and Group-Level Variable Means, Standard Deviations, and Intercorrelations for Relationship Conflict and Relationship Conflict Handling $(\mathrm{N}=96)$.

4. Hierarchical Regression Analysis for Group Performance and Group Member Satisfaction on Task Conflict $(\mathrm{N}=96)$

5. Hierarchical Regression Analysis for Group Performance and Group Member

Satisfaction on Relationship Conflict $(\mathrm{N}=96)$. 45

6. Individual-Level Variable Means, Standard Deviations, and Coefficient Alpha Reliabilities $(\mathrm{N}=271)$ 46

7. Mean Within-Group Agreement (rwg(j)) Coefficients and Group-Level Variable Means, Standard Deviations, and Intercorrelations for Task Conflict and Task Conflict Handling $(\mathrm{N}=52)$ .47

8. Mean Within-Group Agreement (rwg(j)) Coefficients and Group-Level Variable Means, Standard Deviations, and Intercorrelations for Relationship Conflict and Relationship Conflict Handling $(\mathrm{N}=52)$. .48

9. Hierarchical Regression Analysis for Group Performance and Group Member Satisfaction on Task Conflict $(\mathrm{N}=52)$.

10. Hierarchical Regression Analysis for Group Performance and Group Member Satisfaction on Relationship Conflict $(\mathrm{N}=52)$ 50 
1. Plot of the interaction between task conflict and avoiding behavior in the prediction of group performance.

2. Plot of the interaction between task conflict and collaborating behavior in the prediction of group satisfaction.

3. Plot of the interaction between relationship conflict and avoiding behavior in the prediction of group performance

4. Plot of the interaction between relationship conflict and compromising behavior in the prediction of group satisfaction.

5. Plot of the interaction between task conflict and collaborating behavior in the prediction of group satisfaction.

6. Plot of the interaction between relationship conflict and competing behavior in the prediction of group performance (sub-sample).

7. Plot of the interaction between relationship conflict and accommodating behavior in the prediction of group satisfaction (sub-sample).

8. Plot of the interaction between relationship conflict and compromising behavior in the prediction of group satisfaction (sub-sample)

9. Plot of the interaction between relationship conflict and collaborating behavior in the prediction of group satisfaction (sub-sample). 


\section{Introduction}

The use of work groups to perform a variety of organizational tasks has become a common business practice. Groups have the advantage of the collective resources of their members. In addition, organizations staff groups with members from different backgrounds in order to maximize the expertise available to the group. While the resulting diversity of thoughts and ideas has the potential to improve the quality of group outcomes, it also carries with it the inevitability of conflict (Watson, Kumar, Michaelson, 1993). Thus managing conflict is an important aspect of organizational and especially work group life.

Conflict, in general, is defined as a "process in which one party perceives that its interests are being opposed or negatively affected by another party" (Wall \& Callister, 1995, p. 517). Conflict research has spanned six levels of analysis, namely: intrapersonal, interpersonal, intragroup, intergroup, interorganizational, and international (Jehn, 1992; Wall \& Callister, 1995). Group conflict research includes the study of both intragroup and intergroup conflict. Intergroup conflict (Alter, 1990; Messick \& Mackie, 1989) received more attention in the early days of small group research, and is defined as conflict that occurs between groups. Intragroup conflict, defined as conflict occurring among group members within a group, has been the focus of considerable attention in last decade of the study of small groups. This study focuses on conflict at the intragroup level of analysis.

While conflict and small group research have traditionally viewed conflict as necessarily harmful to group productivity (Brown, 1983; Pondy, 1967), more recent studies have shown that certain types of conflict are associated with improved group 
outcomes (Amason \& Sapienza, 1997; Cosier \& Dalton, 1990; Jehn, 1992, 1994, 1995;

Schweiger, Sandberg, \& Ragan, 1986; Schweiger, Sandberg, \& Rechner, 1989). An important finding from this stream of research is the identification of different types of conflict that also have unique effects on group functioning.

Most conflict researchers recognize two types of conflict: (1) task-related conflicts, which result when group members argue over alternatives related to the group's task, and (2) relationship conflicts, which result over interpersonal clashes, and are not directly related to achieving the groups function (Jehn, 1992; Priem \& Price, 1991). In addition, the literature seems to support the existence of a third type of conflict, termed administrative (Jehn, 1992; Shah \& Jehn, 1993) or process conflict (Jehn, 1997). Process conflicts are disagreements over who will do what and the manner in which tasks will be completed.

Jehn (1992) examined project teams at a manufacturing firm and found relationship conflict was negatively associated with group effectiveness, and the effects of task conflict depended on the task type. Task conflict was beneficial to groups performing nonroutine tasks, and harmful to those performing routine tasks. Shah and Jehn (1993) reported a similar result in laboratory task groups. There the effects of conflict on group performance were partly a function of the type of task the group was performing. In decision groups, task conflict enhanced while relationship and administrative conflict lowered group performance. In groups performing motor tasks, all three conflict types were harmful to group performance. Amason (1996) examined these relationships in top management teams and found task conflict related positively while relationship conflict related negatively to both decision quality and affective 
acceptance. Taken together, these results generally support the idea that relationship conflict is detrimental to group performance, yet task conflict, in certain situations and team types, enhances group performance. Jehn (1997) suggests group members promote task conflicts yet avoid or quickly resolve relationship and process conflicts.

The question remains, how do groups effectively manage intragroup conflict? The appropriate behavioral responses of groups to internal conflicts have not been explored. Shah and Jehn (1993) note conflict norms led to an increase in the level of conflict groups experienced, but did not improve the ability of groups to effectively resolve the conflict. Thus the value of understanding group conflict types implies the need to understand how high performing groups manage the different types of conflict effectively. Further, while it is recognized that task conflict has the potential to improve the quality of group outcomes, the issue of how groups should manage task conflict so that it does not backfire potentially harming the group's performance has not been addressed.

Group conflict handling involves behaviors in response to conflict that are directly within the control of the group's members, and thus are of particular importance in understanding and directing the behavior of group members. This study seeks to first extend the interpersonal conflict handling literature from the individual to the group context, and then to examine the effectiveness of group conflict handling in resolving task and relationship conflicts.

The main goal of this research is to examine the relative effectiveness of different group conflict handling styles as a function of group conflict type. And more practically, 
to isolate the patterns of conflict handling that maximize the positive effects of task conflict, while minimizing the negative effects of relationship conflicts.

\section{Literature Review}

\section{Intragroup Conflict}

Intragroup conflict was defined earlier as disagreement among group members. This section reviews the relevant literature on the types, antecedents, and consequences of intragroup conflict.

Types of Intragroup Conflict. From the early years of organizational conflict research, authors have generally distinguished between two broad classes of conflict. Guetzkow and Gyr (1954) distinguished between substantive and affective conflict in decision-making groups. Here substantive conflict was defined as relating to the group's task, while affective conflict was that involving interpersonal relations. Similarly, Coser (1956) introduced goal-oriented conflicts as those arising from individuals' pursuit of specific gains, and emotional conflicts as those arising from interpersonal frustrations.

More recently, Pinkley's (1990) multidimensional scaling analysis of disputant interpretations of conflict supported a bipolar relationship-task dimension. Disputants were found to focus more on either the relationship or task-related issues as integral to the conflict situation. While Pinkley focused on the views of disputants and mediators in an interpersonal conflict, a similar classification has been used to describe intragroup conflicts as well.

Priem and Price (1991) distinguished between social-emotional and taskrelated conflicts in their study of decision-making groups. Jehn's (1992) multidimensional scaling study further supported the application of these conflict 
types to the intragroup context. Jehn found three dimensions necessary to define the underlying structure of intragroup conflict. The dimensions were labeled task content, administrative, and emotional. These were proposed as orthogonal dimensions of group conflict. Emotional conflict was defined as "an awareness by the parties involved that there are interpersonal incompatibilities" (Jehn, 1992, p.10). Task content conflict was defined as " an awareness by the parties involved that there are disagreements about the actual tasks being performed" (Jehn, 1992, p.11). Finally, administrative conflict was defined as "an awareness by the parties involved that there are controversies about aspects of how task accomplishment will proceed"' (Jehn, 1992, p. 12).

Since Jehn's (1992) empirical investigation of intragroup conflict types, research has employed a variety of different labels for the types of conflict groups experience. Some studies have used a two-dimensional approach, while others have used three dimensions. Shah and Jehn (1993) examined emotional, task content, and administrative conflict. Jehn (1994) reports only emotional and task conflict. Amason and Schweiger (1994), Amason (1996), and Amason and Sapienza (1997) investigated cognitive and affective conflict. Jehn (1995) and Jehn, Chadwick, and Thatcher (1997) investigated task and relationship conflict. While the labeling of dimensions has been somewhat inconsistent, all of the above studies measured conflict types using some variation of Jehn's (1992) Intragroup Conflict Scale.

Jehn's (1997) qualitative investigation of conflict types inductively derived three types of intragroup conflict, labeled relationship, task, and process. Here relationship 
conflicts were those focusing on interpersonal relationships, task conflicts were those focusing on the content and goals of the work, and process conflicts were those focusing on how the work gets done. From this point on, I use this labeling format to define the types of intragroup conflict.

Consequences of Intragroup Conflict. A notable finding to come out of the research on conflict types is that different types of conflict have different effects on group functioning. Key findings from this literature are reviewed below.

Jehn (1992) used survey and ethnographic methods to investigate the impact of intragroup conflict on group effectiveness in work groups at a freight transport firm. Results showed emotional conflict was harmful to group performance and attitudinal effectiveness. Administrative conflict was also harmful to group effectiveness, though a certain amount was seen as necessary. The effects of content conflict were dependent upon the type of task the group was performing. Content conflict was associated with improved effectiveness in non-routine groups. In groups performing routine tasks, content conflict was associated with reduced effectiveness.

While Jehn's (1992) model posited the relationship between content conflict and group outcomes would be moderated by task complexity, survey results led her to consider a rival explanation. There was a strong main effect for task complexity that raised the possibility that task complexity directly caused the level of content conflict that in turn, affected group outcomes (Jehn, 1992). According to this sequence, obtained results would support the conclusion that 
non-routine task groups showed more effective conflict patterns and were higher performers, while the patterns of routine task groups were more dysfunctional and the groups were lower performers. In either case, the benefits of content conflict were thought to result from the increased generation of ideas and solutions. As critical discussion of alternatives has a greater potential benefit in non-routine task groups, this explains why content conflict was helpful to groups performing non-routine tasks but not to those performing routine tasks.

Ethnographic results provided some insight into potential explanations for the findings with emotional and administrative conflict. First, members of groups with high amounts of emotional conflict reported increased psychological distress. This especially explains the strong negative relationship between emotional conflict and attitudinal effectiveness. The negative effects of administrative conflict were thought to arise from the resulting "inconsistencies in the group" and time management issues created by the conflict (Jehn, 1992, p. 136).

Shah and Jehn (1993) report similar findings in short term lab groups where again, task type moderated the relationship between conflict types and group performance. The effects of emotional, administrative, and task content conflict were examined. Results showed both emotional and administrative conflict led to decreased group performance on decision and motor tasks. Task-content conflict was associated with improved group performance on the decision making task, and associated with decreased performance on the motor task.

Amason and Schweiger (1994) introduced cognitive and affective conflict to the strategic decision making literature, proposing the two types of conflict as moderators of 
the relationship between team capabilities and interaction processes and key decision making outcomes. A test of the model in two samples of top management teams revealed the cognitive dimension of conflict was generally associated with improved team decision making, while the affective conflict dimension was associated with decreased decision making performance (Amason, 1996). It is also notable that the negative effects of affective conflict on decision quality were significant, while the positive effects of cognitive conflict on decision quality were not significant. This may reflect the importance of other factors, such as group conflict handling, in explaining how beneficial cognitive conflict will be on the group's outcomes.

Priem, Harrison, and Muir (1995) found groups using the dialectical inquiry approach, a technique designed to enhance structured cognitive conflict, showed stronger member acceptance of decisions and satisfaction with the group, than did members of groups using the consensus approach.

Jehn (1997) found groups with high levels of relationship conflict to have lower levels of performance and satisfaction than groups with low levels of relationship conflict. Process conflict was also associated with reduced group performance. The effects of task conflict on group outcomes were dependent upon the conflict's emotionality, resolution potential, acceptability norms, and importance. Specifically, emotionality served as a negative moderator, resolution potential and acceptability norms were both positive moderators, and importance intensified the effects of the other dimensions. Thus task conflict had its most positive effects on group outcomes when it was unemotional and viewed as resolvable and acceptable. 
Taken together, results from this literature highlight the importance of recognizing the different types of conflict, and their varying effects on group outcomes. Thus, not all conflict is the same, and not all conflict is harmful. A second stream of intragroup conflict research investigates factors influencing the types of conflict likely to be present in the group.

Antecedents of Group Conflict. In this section, findings related to the antecedents of relationship and task conflict are presented. The primary aim of this research has been to identify characteristics of groups associated with the different types of conflict.

Amason and Sapienza (1997) examined the effects of team size and two interaction norms, openness and mutuality, on the resulting affective and cognitive conflict. Presumably due to their larger cognitive diversity, larger teams showed higher levels of both types of conflict than did smaller teams. Openness towards conflict was positively associated with the team's level of cognitive conflict. Relationships between openness and mutuality and affective conflict were not significant.

Watson, Kumar, and Michaelsen (1993) examined the performance of culturally homogeneous and culturally diverse lab groups over time. Initially, the performance of more similar groups was higher, but by week 17 there were no performance differences and the diverse groups were identifying problem perspectives and generating solution alternatives better than the homogenous groups. Watson, Kumar, and Michaelsen (1993) state, "diverse groups reported...more difficulty in agreeing on what was important and in working together" (p. 596). This further underscores the importance of understanding conflict processes and their effects on performance. 
Jehn (1994) examined the mediating role of conflict types on the relationship between two aspects of group diversity, group value similarity and group value fit, on group performance and group member satisfaction levels. Findings from this work generally showed relationship and task conflict mediated the effects of group diversity on group outcomes, and again replicated the direct effects of task-related and emotional conflict on group outcomes. Specifically, emotional conflict was negatively related to group performance and satisfaction; task-related conflict was positively related to group performance, and unrelated to group satisfaction.

Jehn, Chadwick, and Thatcher (1997) studied the effects of visible and informational demographic differences, and value congruence on task-related and relationship conflict and subsequent group outcomes. Visible differences were associated with increased relationship conflict, while informational differences were associated with increased task-related conflict. Value congruence was associated with lower levels of both types of conflict.

The above studies all built upon the idea that task conflict is "good," and relationship conflict is "bad," and attempted to isolate predictors of these two types of conflict. This approach is limited in that it views the group as a stable recipient of the conflict process, and seeks to isolate group qualities associated with good and bad conflict. According to current small group theory, groups are complex, dynamic, and adaptive systems (McGrath, 1997). Thus, rather than study factors that will affect the resulting types of intragroup conflict, an approach more theoretically consistent with the current understanding of the group context would be to investigate the reactions of the group to various issues it faces (conflict types) as predictors of the relevant group 
outcomes. In the section to follow, group conflict handling, and its role in offering a more prescriptive approach to the understanding of effective and ineffective conflict patterns is discussed.

\section{Group Conflict Management}

Marks, Mathieu, and Zaccaro (1999) suggest that intragroup conflict management is made up of two types of activities, termed preemptive and reactive. Preemptive conflict management strategies include group level mechanisms that seek to prevent conflict from developing, and guide how it is resolved should it develop (e.g. group norms). Shah and Jehn (1993) found group acceptability norms effect the amount and intensity of resulting group conflicts. Amason and Sapienza (1997) also found team openness towards conflict was associated with the amount of cognitive conflict. Jehn (1997) found these norms develop specific towards the different types of conflict.

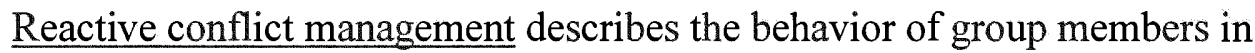
response to a manifest conflict. At the individual level, conflict behavior is an individual's reaction to the perception that one's own and another party's current aspirations cannot be achieved simultaneously (Deutsch, 1973; Pruitt \& Rubin, 1986). At the intragroup level, group conflict handling describes the reactive responses of group members to conflicts. This investigation focuses on the reactive mechanisms of group conflict management activities.

While previous research has not examined the behavior of group members in response to intragroup conflict, individual responses to interpersonal conflict have been studied extensively. Much research in this domain has built upon the five-part typology of Blake and Mouton (1964). This framework is based upon a two dimensional system 
where concern for people and concern for the production of results form theoretically orthogonal dimensions defining five styles of handling interpersonal conflict. These dimensions were later interpreted as concern for the production of results for oneself and concern for the production of results for the opponent (van de Vliert \& Euwema, 1994). The five styles are: accommodating, avoiding, compromising, problem solving, and forcing (Kilmann \& Thomas, 1977; Rahim, 1983a, 1983b).

Thomas (1976) reinterpreted Blake and Mouton's theory describing the two dimensions of distribution and integration. According to their reinterpretation, the distributive component of a given conflict strategy describes the extent to which conflict behavior is meant to maximize the unequal outcomes of the conflict parties, while the integrative component describes the extent to which conflict behavior is meant to maximize the joint outcomes of the conflict parties. van de Vliert (1990) found support for this framework.

Sternberg and Dobson (1987) investigated conflict management styles in undergraduate students utilizing an entirely different empirically derived framework. Students indicated their preferred conflict management styles based upon sixteen potential behaviors. Factor analysis supported a two-dimensional framework, labeled active-passive and intensify-mitigate. van de Vliert (1990) reanalyzed this data using multidimensional scaling, deemed a more appropriate analysis strategy given their sample size to item pool ratio, and again found a two-dimensional solution fit the data best. These dimensions supported the integration/distribution components of conflict behavior. 
The confusion over the appropriate classification and labeling of the dimensions underlying conflict behavior led van de Vliert and Euwema (1994) to construct a metataxonomy incorporating the above typologies. Their study reconciled conflict handling as delineated in the above research into one metataxonomy with the dimensions agreeableness and activeness. Agreeableness describes "the extent to which conflict behaviors make a pleasant and relaxed rather than unpleasant and strainful impression" (van de Vliert \& Euwema, 1994, p.676). Activeness describes "the extent to which conflict behaviors make a responsive and direct rather than inert and undirect impression" (van de Vliert \& Euwema, 1994, p. 676). van de Vliert and Euwema concluded that "distinct conflict behaviors are compounds of agreeableness and activeness...given these behavioral interrelations, rather than excluding each other, the modes or styles may well occur simultaneously" (p. 685).

The aforementioned fascination with conflict styles as predispositions, and the underlying dimensions describing them has led to what Wall and Callister (1985) term "two dimensional thinking." Two arguments against this framework have been proposed. Wall and Callister (1985) argue the framing of conflict handling along these dimensions leads to the conclusion that effective conflict handling is synonymous with outcome maximization. These authors argue instead that a broader outcome scope needs to be used to judge the effectiveness of conflict behavior, and specifically, that the effect of conflict handling on disputant relationships should be a key outcome for future research. This argument seems especially relevant to the study of conflict at the intragroup level, as one function of a group is to fulfill the relationship or socio-emotional needs of its members. 
Secondly, while Blake and Mouton's (1964) theory advocates a "one best approach" to handling conflict, many conflict researchers emphasize the inadequacy of this framework in describing actual conflict behavior (van de Vliert, Euwema, \& Huisans, 1995; van de Vliert \& Kabanoff, 1990; van de Vliert, 1990). While these theories may effectively describe the components of conflict behavior, these researchers argue it is the pattern of behaviors as opposed to a single behavioral style that more accurately describes conflict handling behavior.

van de Vliert, Euwema, and Huismans (1995) examined the effectiveness of conglomerations of conflict behavior in resolving conflict with a supervisor and a subordinate. Independent raters qualitatively coded videotaped conflict episodes to assess seven components of conflict behavior. The components used were the same as those in the five part typologies, with two additional types of forcing, although conflict handling was represented by the resulting means and patterns of covariation, as opposed to a single score. Results showed conflict conglomerations were more effective when forcing was removed and/or process controlling added. For subordinates, removing the avoiding component increased effectiveness. While for supervisors, adding the accommodating component increased effectiveness. Results from this work illustrate the importance of viewing conflict as a pattern of behavioral components as opposed to a distinct conflict mode.

Conclusion

In sum, this study examines the effectiveness of groups' behavioral responses in resolving task and relationship conflicts. As discussed earlier, effective group conflict handling in a group setting should maximize both the quality of the group's output and 
member relationships. Group outcomes are operationalized here as the two functions essential to a group's success: group performance and group member satisfaction. In light of the research on conflict types, it seems that "effective" conflict handling is partly a function of the type of conflict being addressed. Different responses are likely to be more and less effective in handling the different types of conflict. While one pattern of conflict handling may be associated with improved group outcomes when used as a response to task-related disputes, the same pattern may be associated with decreased outcomes in response to relationship disputes.

Utilizing van de Vliert and Euwema's (1994) framework, the agreeableness and activeness dimensions underlying the components or styles of conflict handling behavior may provide some insight towards an understanding of the differences in effectiveness of the different components in response to the two types of conflict. The following hypotheses are designed to test the predictions that effective group conflict handling is a function of the type of conflict faced by the group as well as the behavior used in response to that conflict.

\section{Hypotheses}

One consistent finding has been that task conflict has the potential to improve the quality of group outcomes. This relationship with performance is likely to result only when active styles of handling conflict are used. If task related differences are not brought into the open, they cannot be expected to help performance. Hence, a positive relationship would be expected between task conflict and group performance in groups whose overall conflict handling pattern is high on the active styles of competing, collaborating, and compromising. A negative relationship between task conflict and 
group performance would be expected in groups using the avoiding and accommodating styles. Essentially, groups with high amounts of task conflict who report using avoidance and accommodative conflict handling behaviors are those whose members have a variety of ideas, opinions, and suggestions, and yet do not voice them.

Hypothesis 1a: The use of active conflict handling behaviors (collaborating, compromising, and competing) will moderate the relationship between task conflict and group performance, such that task conflict will have a stronger (positive) relationship with performance in groups that use more active conflict handling behaviors, than in groups using less active conflict handling behaviors. Hypothesis $1 \mathrm{~b}$ : The use of passive conflict handling behaviors (avoiding and accommodating) will moderate the relationship between task conflict and group performance, such that task conflict will have a weaker (positive) relationship with performance in groups using more passive conflict handling behaviors than in groups using less passive conflict handling behaviors.

The effectiveness of various conflict handling behaviors should be different for relationship and task conflict when it comes to the prediction of group performance. While more active approaches to task conflicts may be expected to have a positive effect on group performance, more passive approaches to relationship conflict are likely to relate to increased group performance. For instance, groups that tend to accommodate one another in response to task related disagreements may not generate as many novel ideas and would be expected to have lower performance outcomes than groups that use less accommodation, the opposite seems likely for relationship conflict. Given that relationship conflicts, defined as interpersonal differences or clashes, are often 
unresolvable, groups that accommodate one another in response to relationship conflicts would be expected to outperform groups that do not avoid them. On the other hand, groups whose members use competing and collaborating in their responses to relationship issues are likely to have decreased performance, as they're spending valuable time discussing issues unrelated to their ultimate "product." Thus, when responding to relationship conflict, groups whose conflict handling patterns are high in the less active avoiding and accommodating components and low in the more active collaborating, compromising, and competing components will likely be the most effective.

Hypothesis 2a: The use of active conflict handling behaviors (collaborating, compromising, and competing) will moderate the relationship between relationship conflict and group performance, such that relationship conflict will have a stronger (negative) relationship with performance in groups that use more active conflict handling behaviors than in groups using less active conflict handling behaviors.

Hypothesis $2 \mathrm{~b}$ : The use of passive conflict handling behaviors (avoiding and accommodating) will moderate the relationship between relationship conflict and group performance, such that relationship conflict will have a weaker (negative) relationship with performance in groups that use more passive conflict handling behaviors than in groups using less passive conflict handling behaviors. In examining the effects of group conflict on group performance, different conflict handling behaviors are likely be more and less effective depending on the type of conflict. For group member satisfaction, the agreeableness dimension is used as the framework for our hypotheses. It seems likely that both types of conflict will have 
negative relationships with group member satisfaction, though the use of more agreeable conflict handling behaviors has the potential to mitigate this effect. Thus for both relationship and task conflict it is expected that the negative effects of conflict on satisfaction with the group will be reduced by the use of the more agreeable collaborating and accommodating behaviors, and strengthened by the more disagreeable compromising, avoiding, and competing behaviors.

Hypothesis 3a: The use of agreeable conflict handling behaviors (collaborating and accommodating) will moderate the relationship between task conflict and group satisfaction, such that task conflict will have a weaker (negative) relationship with satisfaction in groups using more agreeable conflict handling behaviors than in groups using less agreeable conflict handling behaviors. Hypothesis $3 \mathrm{~b}$ : The use of disagreeable conflict handling behaviors (avoiding, compromising, and competing) will moderate the relationship between task conflict and group satisfaction, such that task conflict will have a stronger (negative) relationship with satisfaction in groups using more disagreeable conflict handling behaviors than in groups using less disagreeable conflict handling behaviors.

Hypothesis 4a: The use of agreeable conflict handling behaviors (collaborating and accommodating) will moderate the relationship between relationship conflict and group satisfaction, such that relationship conflict will have a weaker (negative) relationship with satisfaction in groups that use more agreeable conflict handling behaviors than in groups using less agreeable conflict handling behaviors. 
Hypothesis $4 \mathrm{~b}$ : The use of disagreeable conflict handling behaviors (avoiding, compromising, and competing) will moderate the relationship between relationship conflict and group satisfaction, such that relationship conflict will have a stronger (negative) relationship with satisfaction in groups that use more disagreeable conflict handling behaviors than in groups using less disagreeable conflict handling behaviors..

\section{Method}

\section{$\underline{\text { Sample }}$}

Participants included 517 undergraduate business administration students currently enrolled in one of ten sections of an introductory business course at one of two large southeastern universities. As a part of their course requirements, participants were assigned to class project groups and completed a group project. The size of the groups ranged from three to eight. Of the 517 students, 391 returned usable surveys for a response rate of $76 \%$. Overall, the 517 students comprised 101 groups. To be included in group-level analyses, at least two members of the group had to return usable surveys. Ninety-six groups met this criterion and were used in the analyses.

Procedure

Although five classes were used, the projects assigned to the groups were all similar in that they were non-routine and performance included some judgment of group innovativeness. The literature shows the effects of conflict on group outcomes are strongest in groups performing novel tasks, thus only groups with projects of this nature were selected. In the end, groups in introductory courses in strategic management, organizational behavior, inter-group relations, and marketing were deemed appropriate. 
This included ten sections in all. All groups were assigned a project requiring critical analysis and integration of their course material. The types of projects ranged from the identification and critical analysis of an existing behavioral problem in an organization to the design and development of a marketing plan for a new product.

The survey instrument was administered one to two weeks prior to the due date for the project. This time was selected to allow the groups as much time possible to interact and experience conflict. For six of the ten sections, the principal investigator visited the class and gave a brief description of the study. Students were informed their participation was voluntary, and informed consent forms were then passed out and collected. Next the survey instrument (see Appendix A) was completed by participants and returned to the experimenter during the class period. Students were then thanked for their participation. Performance data were collected from the course instructors at the end of the semester.

For four of the sections, the course instructor served as the experimenter in distributing the survey instrument. For these sections care was taken to protect the identity of participants. The instructor collected all surveys together and the only identification placed on the survey was the group number.

\section{Measures}

Conflict Types. Jehn's (1992) Intragroup Conflict Scale (see B for the complete scale) was used to assess the amounts of relationship and task conflict present in each group. A sample item from the relationship conflict scale is, "How much interpersonal friction has there been in your work group?" A sample item from the task conflict scale is, "How much disagreement has there been in your group about your project?" All 
responses were made on five-point Likert scales ranging from "None or Hardly Any" to "A Great Deal." Measurement was made at the individual level and scores were later averaged within each group to comprise the average level of perceived relationship and task conflict for the group.

Conflict Handling. The five dimensions of group conflict handling were assessed using the 28-item ROCI-II (Rahim, 1983a, 1983b). All items were reworded to reflect the project group as the referent, and some items were reworded slightly to reflect the type of conflict the group was recalling (see Appendix B for a list of the reworded items). The items were asked two times to asses group conflict handling behavior in response to each type of conflict individually. For task conflict, the instructions at the top of the page read:

"Task conflict occurs in work groups when there are disagreements over ideas and alternatives related to your group's project. How have the members of your group handled differing opinions, ideas, and alternatives related to your group's task in the past? For these questions, think only about task-related issues your group has faced."

The 28 ROCI-II items followed these instructions. Two sample items are, "We have avoided open discussion of our differences of opinion", and "We have generally negotiated so that a compromise could be reached." Responses were on 5-point scales ranging from "We Have Almost Never Done This" to "We Have Almost Always Done This." These responses were employed to capture the recall of past behavior of the group's members in response to conflicts.

For relationship conflict, the instructions read: 
"Relationship conflict occurs in work groups when there are interpersonal differences and disagreements. These disagreements are not directly related to the task assigned to your group. How have the members of your group handled interpersonal differences (e.g. personality problems) in the past? For these questions, think only about relationship issues that your group has faced."

The 28 ROCI-II items followed these instructions. Two sample items are, "We have avoided open discussion of our interpersonal differences", and "We have generally negotiated so that a compromise could be reached." Responses were on 5-point scales ranging from "We Have Almost Never Done This" to "We Have Almost Always Done This." While group conflict handling was measured by individual group members' responses, items were all worded to reflect the group. Responses within groups were then averaged to represent the average perception of the group's conflict handling behavior.

Group Outcomes. The primary functions of a work group are to accomplish a given goal, and to foster positive working relationships within the group so that future tasks may be successfully completed (Hackman, 1983). Effective conflict management, then, should have positive effects on both the quality of the group's output and members' satisfaction with the group.

Group performance was measured using the course instructor's evaluation of the group project. Five instructors participated in this study, and served as the performance evaluator for his/her project groups. One of the problems with the full sample may have been that evaluations were in part based on different criteria. Thus, supplemental analyses were also conducted examining only a subset of the groups where the two 
instructors used the same five criteria to evaluate the groups was used. These criteria were: creativity/originality, presentation, organization/completeness, depth of research and analysis, and application of course concepts.

Group member satisfaction was measured using two items taken from Priem, Harrison, and Muir (1995). These items read "Working with this group has been an enjoyable experience" and "I would like to work with this group in the future." Responses were made on five-point Likert scales ranging from "Strongly Agree" to "Strongly Disagree."

Data Analysis

Descriptive statistics. Means, standard deviations, and coefficient alpha internal consistency reliabilities were first computed for each scale using the individual survey responses. Intercorrelations between conflict types, conflict handling, and the outcome measures were also computed. Correlations between the independent, moderator, and dependent variables and the pattern and number of meetings the group had, the division of work within the group, the initial level of familiarity of group members, and the amount of interaction the group had throughout the semester were all examined to determine important covariates.

Within-group agreement. The measurement of relationship and task conflict and group conflict handling behavior contain individual assessments of the same target. To examine the relationships of these variables with group level performance and satisfaction, scores must first be aggregated. Prior to aggregating these scores, withingroup agreement coefficients $\left(\mathrm{r}_{\mathrm{wg}(j)}\right)$ were computed in the manner suggested by James, Demaree, and Wolf (1984). Following this analysis, group-level composite variables 
were computed as the average of the scale scores for the members of each group. These composites were then used in all remaining analyses.

Tests of hypotheses. Hierarchical multiple regression was used to test main effects and moderation. Moderation hypotheses were tested in three steps. In the first step, the dependent variable (either group performance or group member satisfaction) was regressed on the independent variable (either relationship or task conflict). In step 2 the moderator variable (conflict handling) was entered into the equation. Step 3 involved entering a multiplicative term (independent variable $\mathrm{X}$ moderator variable) to the equation. A significant increase in the percent of variance explained $\left(\Delta R^{2}\right)$ in the dependent variable by the multiplicative interaction term is indicative of a moderator effect. This procedure was conducted for each of the two dependent variables, the two independent variables, and the five moderator variables. In total, twenty moderated regression lines were computed. The procedure outlined in Cohen and Cohen (1983) was then used to examine the direction of moderator effects.

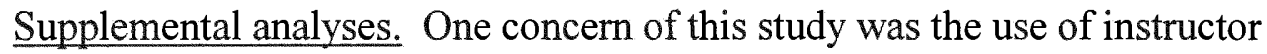
ratings as the performance indicator. The sample included groups from four different courses and five instructors. Although the types of tasks assigned to the groups were all the same (non-routine), there were some differences in the content of the assignments and the rating systems of the instructors. Additionally, since each group only had one instructor, and each instructor only rated his/her groups, the comparability of the performance ratings obtained by different instructors could not be directly assessed. However, for a subset of the groups, both the assigned project and scoring system used by the two instructors were identical. As one method of investigating this issue, all 
analyses were conducted on both the sub-sample of more similar groups and on the full sample and then results obtained from both were compared.

Participants in the sub-sample included 258 undergraduate business administration students currently enrolled in one of two sections of an introductory marketing course. The size of the groups ranged from four to six. Of the 258 students, 180 returned usable surveys for a response rate of $70 \%$. Overall, the 258 students comprised 55 groups. To be included in group-level analyses, at least two members of the group had to return usable surveys. Fifty-two groups met this criterion and were used in the supplemental analyses.

For comparability with the full sample, the groups comprising the sub-sample were all students in introductory marketing classes. These groups all completed an identical project and were rated according to the same four criteria. The group assignment for these groups was to think of a new product or use an existing product as the basis for an original marketing plan. The groups were given approximately eight weeks to complete the projects, and then all projects were presented at a trade show. During the week prior to the trade show, surveys were administered during class to all participants.

\section{Results}

Descriptive statistics and reliability. Table 1 (see page 41) reports the means, standard deviations, and internal consistency reliabilities $(\alpha)$ for all scales using the individual-level survey responses for the full sample $(N=391)$. All variables had minimum values of one and maximum values of five, corresponding with the scale 
anchors. Scale reliabilities were all above .70 , ranging from .75 to .90 .

Within-group agreement. Once individual-level scale properties were examined, within-group agreement coefficients $\left(\mathrm{r}_{\mathrm{wg}(\mathrm{j})}\right)$ were examined to justify aggregation of individual responses to the group level. Table 2 (see page 42) reports the median within group agreement coefficients for task conflict; Table 3 (see page 43) reports the median agreement coefficients for relationship conflict. Agreement coefficients ranged from 86 to .98 . Group satisfaction had the lowest within-group agreement with the median $r_{w g(j)}$ equal to .86 .

Correlations. Table 2 also presents the group level variable intercorrelations for task conflict and task conflict handling behavior. Task conflict correlated -.17 (ns) with group performance, and $-.47(\mathrm{p} \leq .01)$ with group satisfaction. Correlations between task conflict and the five conflict handling behaviors showed correlations between .07 (ns) for competing and $-.40(\mathrm{p} \leq .01)$ for accommodating. Task conflict was also significantly related to collaborative $(\underline{r}=-.22, \mathrm{p} \leq .05)$ and compromising $(\underline{\mathrm{r}}=-.22, \mathrm{p} \leq .05)$ conflict behaviors, and was not significantly related to the use of avoidance behaviors $(\underline{r}=-.15$, ns). The correlation between group performance and group member satisfaction was .10 (ns). The correlation between task and relationship conflict was .61 $(\mathrm{p} \leq .01)$.

Table 3 presents the group level variable intercorrelations for relationship conflict and relationship conflict handling behavior. The correlation between relationship conflict and group performance was -.10 (ns). The correlation between relationship conflict and group satisfaction was $-.55(\mathrm{p} \leq .01)$. The correlations between relationship conflict and the five types of conflict handling ranged from -.03 (ns) for avoiding to $-.30(\mathrm{p} \leq .01)$ for collaborating. Relationship conflict was also significantly related to the use of 
compromising $(\underline{\mathrm{r}}=-.21, \mathrm{p} \leq .05)$ and accommodating $(\underline{\mathrm{r}}=-.25, \mathrm{p} \leq .05)$ behaviors, but was not significantly related to the use of competitive behaviors $(\underline{r}=.05)$.

Demographic variables, group member familiarity and both the amount and frequency of the group's interaction were examined as potential covariates. Correlations between each of these variables and each key study variable were all small and nonsignificant, and so these variables were excluded from all subsequent analyses.

Regressions. All hypotheses were tested using hierarchical multiple regression. Results for task conflict with both group performance and group satisfaction (H1 \& H3) are reported in Table 4 (see page 44). Results for relationship conflict with both group performance and group satisfaction (H2 \& H4) are reported in Table 5 (see page 45).

Examining the results for group performance regressed on the interactions of task conflict and the active conflict handling behaviors (collaborating, compromising, and competing) did not support hypothesis $1 \mathrm{a}$. The converse, hypothesis $1 \mathrm{~b}$ did receive some support. In examining the passive (avoiding and accommodating) behaviors, the task conflict*avoiding interaction led to a marginally significant increase in the variance accounted for $\left(\Delta \mathrm{R}^{2}=.03, \mathrm{p} \leq .10\right)$ in performance. The procedure outlined in Cohen and Cohen (1983) was next used to examine the nature of the interaction (please see Figure 1 on page 51). For groups who reported high use of avoiding, task conflict showed a strong negative relationship with performance. While for groups reporting low use of avoiding, the relationship was close to zero. The interaction of task conflict and the accommodating component did not significantly add to the prediction of performance.

Results for task conflict and group satisfaction (H3) are also reported in Table 4 (see page 44). Hypothesis 3 a received some support. One of the agreeable conflict 
handling behaviors (collaborating) showed a marginally significant interaction with task conflict $\left(\Delta \mathrm{R}^{2}=.02, \mathrm{p} \leq .10\right)$. The other agreeable behavior, accommodate, did not show a significant interaction. Figure 2 (see page 52) displays the interaction plot for task conflict and collaborating. The relationship between task conflict and group member satisfaction was more negative as the use of collaborative conflict handling decreased.

Hypothesis $3 \mathrm{~b}$ held that disagreeable behaviors (competing, compromising, and avoiding) would negatively moderate the relationship between task conflict and group satisfaction. We did not find support for this effect.

Table 5 (see page 45) reports the results for relationship conflict and group performance (H2). Only the avoiding style had a significant moderating effect on the relationship between relationship conflict and group performance $\left(\Delta \mathrm{R}^{2}=.05, \mathrm{p} \leq .05\right)$. Plotting this interaction (please see figure 3 on page 53) revealed a positive effect of relationship on group performance when avoiding was low, and a negative effect when avoiding was high. Thus a positive moderator effect (opposite H2a) was found. Neither of the passive conflict handling behaviors (avoiding and accommodating) showed significant interactions with relationship conflict, and so $\mathrm{H} 2 \mathrm{~b}$ was not supported.

Table 5 (see page 45) also reports the results for relationship conflict and group member satisfaction. Only the compromising conflict handling style showed a significant moderator effect. Examining the interaction plot for relationship conflict and group member satisfaction (please see Figure 4 on page 54) at one standard deviation above the mean, at the mean, and at one standard deviation below the mean for compromising, showed the relationship between relationship conflict and group performance was more negative as the use of compromising decreased. This is indicative of a negative 
moderating effect, and is opposite hypothesis 4's prediction. None of the agreeable conflict handling behaviors showed significant moderator effects with group satisfaction, and so $\mathrm{H} 3 \mathrm{a}$ was not supported.

Supplemental Analyses

Descriptive statistics and reliability. Table 6 (see page 46) reports the means, standard deviations, and internal consistency reliabilities $(\alpha)$ for all scales using the individual-level survey responses for the sub-sample of 52 groups. As discussed earlier, separate analyses were performed on a subset of highly homogenous groups for comparability. For the reduced sample, scale reliabilities were all above .70 , ranging from .71 to .90 .

Within-group agreement. Within-group agreement coefficients $\left(\mathrm{r}_{\mathrm{wg}(\mathrm{j})}\right)$ were once again examined to justify aggregation of individual responses to the group level. Table 7 (see page 47) reports the median within group agreement coefficients for task conflict; Table 8 (see page 48) reports the agreement coefficients for relationship conflict. All but one value were above .86. Group satisfaction had the lowest within-group agreement with the median $r_{w g(j)}$ equal to .71 .

Correlations. Table 7 (see page 47) also presents the group level variable intercorrelations for task conflict and task conflict handling behavior. Task conflict correlated -.15 (ns) with group performance, and $-.53(\mathrm{p} \leq .01)$ with group satisfaction. Correlations between task conflict and the five conflict handling behaviors showed correlations between $.00(\mathrm{~ns})$ for competing and $-.51(\mathrm{p} \leq .01)$ for accommodating. The correlation between group performance and group member satisfaction was .06 (ns). 
Table 8 (see page 48) presents the group level variable intercorrelations for relationship conflict and relationship conflict handling behavior. The correlation between relationship conflict and group performance was .15 (ns). The correlation between relationship conflict and group satisfaction was $-.57(\mathrm{p} \leq .01)$. The correlations between relationship conflict and the five types of conflict handling ranged from -.11 (ns) for competing to -.19 (ns) for collaborating. None of the correlations between relationship conflict and relationship conflict handling were statistically significant.

Regressions. All hypotheses were again tested using hierarchical multiple regression utilizing only the sub-sample of homogenous cases described above. Results for task conflict and group performance (H1a \& H1b) are reported in Table 9 (see page 49). As can be seen by examining the change in $\mathrm{R}^{2}$ at the third step, none of the interaction effects were significant, and hypotheses $1 \mathrm{a}$ and $1 \mathrm{~b}$ were not supported.

Table 9 also reports the results for task conflict and group member satisfaction. Only the collaborating component interacted with task conflict to predict group satisfaction $\left(\Delta \mathrm{R}^{2}=.04, \mathrm{p} \leq .10\right)$. Examining the shape of the interaction (please see Figure 5 on page 55) showed this effect was in support of hypothesis $3 a$. The use of the agreeable, collaborative conflict handling behavior mitigated the harmful effects of task conflict on group member satisfaction so that in groups reporting frequent use of collaboration, task conflict was only slightly negatively related to group satisfaction, while in groups reporting infrequent use of collaboration, there's a more negative relationship between task conflict and group satisfaction. The other agreeable style (accommodating) did not produce a significant interaction, nor did the three disagreeable conflict behaviors. Thus hypothesis $3 \mathrm{~b}$ was not supported. 
Table 10 (see page 50) reports the results for relationship conflict and group performance. Only the competing style had a significant moderating effect $\left(\Delta R^{2}=.08, p\right.$ $\leq .05$ ) on the relationship between relationship conflict and group performance. Examining the shape of the interaction (please see Figure 6 on page 56)) showed relationship conflict was positively related to performance for groups using competitive conflict handling, and was negatively related to performance for groups not using competitive conflict handling. Thus a positive moderator effect (opposite H2a) was found. Neither of the passive conflict handling behaviors (avoiding and accommodating) showed significant interactions, and so $\mathrm{H} 2 \mathrm{~b}$ was not supported.

Table 10 also reports the results for relationship conflict and group member satisfaction. Collaborating $\left(\Delta \mathrm{R}^{2}=.03, \mathrm{p} \leq .10\right)$, accommodating $\left(\Delta \mathrm{R}^{2}=.05, \mathrm{p} \leq .05\right)$, and compromising $\left(\Delta \mathrm{R}^{2}=.06, \mathrm{p} \leq .06\right)$ all significantly interacted with relationship conflict in predicting group satisfaction. Examining the shape of the interactions (please see Figures 7 thru 9 on pages 57 to 59) showed in all three cases, increased use of the conflict behavior reduced the harmful effects of relationship conflict on group member satisfaction. Both of the agreeable conflict handling styles (collaborating and accommodating), showed significant positive moderator effects and provide strong support for hypothesis 4a. However, compromising has been classified as a disagreeable behavior (van de Vliert \& Euwema, 1994) and thus this interaction is opposite the anticipated direction. These results support the use of compromising as an effective way to handle relationship conflict. One potential explanation for this finding is that participants viewed compromising as more agreeable than disagreeable. Support for this explanation can be found in the correlation matrix in Table 8 (see page 48). Here the 
compromising component is the most closely related to accommodating and collaborating (agreeable behaviors) and less related to avoiding and competing (disagreeable behaviors). None of the other disagreeable conflict handling behaviors (avoiding and competing) showed significant moderator effects with relationship conflict, and so hypothesis $4 \mathrm{~b}$ was not supported.

Results from both the full and sub sample showed some consistent findings. In both, the use of collaborating reduced the harmful effects of task conflict on group satisfaction, while the use of compromising reduced the harmful effects of relationship conflict on group satisfaction.

Results from both sets of analyses were also comparable in their failure to show interaction effects between the accommodating, compromising, collaborating, and competing behaviors and task conflict to predict performance. With respect to group satisfaction, task conflict did not interact with avoiding, accommodating, compromising, or competing in either sample. Similar patterns were present for relationship conflict as well. Accommodating, compromising, and collaborating failed to interact with relationship conflict in the prediction of performance in both samples. Similarly, avoiding and competing failed to interact with relationship conflict in the prediction of group satisfaction.

Finally, some discrepant findings can also be seen in comparing the two sets of analyses. For the full sample, avoiding led to more negative relationships between both types of conflict and group performance. However, in the sub-sample, the avoiding component did not produce a significant interaction with either relationship or task conflict. In the sub-sample, the competing dimension was found to negatively moderate 
the effects of relationship conflict on performance, while in the full sample the competing dimension did not show an interaction effect. Also in the sub-sample only, collaborating and accommodating negatively moderated the effect of relationship conflict on group satisfaction. This effect was not observed in the full sample.

\section{Discussion}

Conflict is an inevitable part of the interactions individuals have with one another and is therefore inherent to nearly all small group settings. Prior research has demonstrated the importance of viewing conflict as multidimensional, with different dimensions having unique effects on group outcomes. Recent findings in this area indicate that task conflict has the potential to improve group outcomes, while relationship conflict only undermines the performance and satisfaction of groups (Amason, 1996; Amason \& Sapienza, 1997; Jehn, 1992; 1994; 1995; 1997). These researchers have suggested the key to obtaining the benefits of conflict without incurring the costs is to promote task conflict and discourage relationship conflict (Amason, 1996; Jehn, 1995). However, research to date has not formally examined these predictions. The current study extends the intragroup conflict literature by first providing an explanation of how conflict handling behavior is likely to have an interactive, rather than direct, effect on the outcomes of conflict, and next by empirically exploring the role of five conflict handling behaviors in determining the effects of conflict on group outcomes.

The current study suggested relationships between conflict and group outcomes depend, at least in part, upon the group's handing of the conflict. Task conflict handled in an active manner was expected to promote group performance, while passively regarded task conflict was not. Conversely, relationship conflict is by definition due to 
interpersonal incompatibilities and is therefore more difficult to resolve and less likely to contribute to group performance. So we would expect relationship conflict to be less negatively related to performance when the more passive handling behaviors are used. Thus the active components of competing, collaborating, and compromising were examined as positive moderators of the relationship between task conflict and group performance; and the passive components of avoiding and accommodating were examined as moderators of the relationship between relationship conflict and group performance.

In the current sample of non-routine task groups, results showed task conflict's relationship with group performance was influenced by the group's use of avoidance. In groups that avoided task conflict there was a strong negative relationship between task conflict and group performance, while in groups that used below average amounts avoidance in response to task conflict, there was almost no relationship between task conflict and group performance. This finding was consistent with prior predictions. Works by Jehn (1992; 1994; 1995; 1997), Amason (1996), and Amason and Sapienza (1997) have investigated conflict in a variety of groups ranging from production teams to top-management-teams, and all have suggested groups encourage task conflict for the benefit of their performance.

These authors have also found relationship conflict to be harmful to group productivity and have therefore advised work groups to avoid or discourage relationship conflict. Results from this study, however, yielded some very unexpected findings with regard to relationship conflict. In fact, relationship conflict was positively related to group performance in groups that did not avoid the conflict, while the relationship was 
negative in groups that did avoid it. Rather than suggest relationship conflict be avoided, these findings suggest relationship conflict will not harm and may even improve the performance of the group so long as it is not avoided.

Another surprising finding with relationship conflict was observed in the supplemental analyses. Competitive handling of relationship conflict enabled it to improve group performance. On the other hand, groups that reported very low use of competition were found to have a negative relationship between relationship conflict and group performance. This result suggests that if groups use competition to resolve relationship conflicts, their conflict will have a positive effect on performance, however if they do not use competition, their conflict will impair their performance. This finding was not observed in the full sample, thus opening up the possibility that something specific to the marketing project groups fostered this effect.

Interestingly, this seems consistent with the full sample results for avoiding. While competing and avoiding are not polar opposites, both competing and "not avoiding" represent active approaches to conflict handling. Thus when groups face relationship conflict, these results suggest the use of active conflict handling behavior. One possible explanation is that through the active management of relationship conflict, groups are better able to interact with one another and in turn perform better than groups that avoid the conflict. For groups using competing the members are facing the conflict, reaching some form of understanding, and are then able to continue with their task. On the other hand, groups avoiding relationship conflict may be avoiding one another not only in response to the conflict but also as a general way of relating to one another. 
The current study also followed up on research that has shown conflict to have important implications for the affective states of group members, and specifically on their levels of satisfaction with their group. The agreeable dimension of conflict handling was posited to distinguish between effective and ineffective handling of conflict in terms of group satisfaction. For both types of conflict, handling the conflict with the agreeable behaviors (collaborating and accommodating) was predicted to mitigate its negative effects on group satisfaction. Results supported this prediction. In both analyses, collaborative behavior positively moderated the relationship between task conflict and group satisfaction, while compromising positively moderated the relationship between relationship conflict and group satisfaction. The supplemental analyses also provided some evidence for accommodating and collaborating as effective ways of handling relationship conflict to minimize its harmful effects on satisfaction.

These findings suggest agreeable handing of conflict led to more positive affect towards the group, though results from the full sample suggest different behaviors are more effective for the two types of conflict. In both analyses, collaborating had the most positive effect on the relationship between task conflict and group satisfaction, while compromising had the most positive effect on the relationship between relationship conflict and group satisfaction. This may be due to the differences in the nature of these conflicts. Task conflicts are the result of differing ideas, and often these differing ideas can be integrated to result in a greater outcome than would be obtained by the adoption of either idea exclusively. This would explain why responding to task disagreements with collaboration reduced the negative affect created by the task conflict.

On the other hand, compromising, not collaborating was consistently observed to 
have this effect for relationship conflict. Relationship conflicts are often due to differences in more stable individual characteristics, and so collaboration may not be a viable means of resolving these problems. In the case of relationship conflict, resolution is more likely the attainment of a constructive working relationship, as opposed to a solution that integrates the wishes of both parties, as is desired with task conflict. It seems compromising would be a clear way of reaching a solution to relationship conflict that minimizes the damage to the group members' affect.

These findings have important implications for groups and managers on how to effectively handle task and relationship conflict in group settings. While both types of conflict showed strong negative relationships with satisfaction, certain ways of handling the conflicts significantly weakened those negative relationships. In responding to task conflict, collaboration was effective. In resolving relationship conflicts, compromising was consistently effective, while some support was also found for the effectiveness of accommodating and collaborating.

This area of study has generally produced suggestions that groups differentially promote and discourage different types of conflict. By contrast, the results of this study provide groups a more active role in the conflict management process by identifying behaviors that completely alter the effect of conflict on their performance and satisfaction. The saying, "what you say isn't as important as how you say it," may be the case when it comes to handling intragroup conflict. That is, group outcomes may not be as much a function of what a group disagrees about, but more importantly how the group handles the resolution process.

It is a widely accepted viewpoint that conflict is natural state of events that results 
from almost any human interaction, and so this research makes a significant contribution by highlighting the importance of group conflict handling behavior. This work provides initial support for group conflict handling as both theoretically important due to its effects on key conflict-outcome relationships and practically meaningful in its ability to offer groups an active way to manage the effects of their conflict.

\section{$\underline{\text { Limitations }}$}

While this study makes an important and meaningful contribution to the literature on intragroup conflict, some important limitations merit discussion. A central limitation of this research was the measurement of group performance. Group performance was only assessed by one rater, the course instructor, and so the reliability of this measure could not be assessed. These project groups were selected because they offered an opportunity to study groups of business school students performing tasks similar to those of the groups this study seeks to generalize results to. Research on intragroup conflict has shown conflict to have the potential to benefit groups only when the task is nonroutine (Jehn, 1995), and so these groups all met this criterion. A tradeoff to studying naturally occurring non-routine groups, was the unavailability of multiple raters of performance. Possibly due to this shortcoming, few results were found with performance. Future studies should examine these relationships using multiple performance criteria.

Another limitation is the cross-sectional nature of the study. Conflict is a process that unfolds over time (Wall \& Callister, 1995; Thomas, 1976). The underlying issue of a conflict and the behavior used to respond to the conflict are interdependent and cyclical. That is, conflict somewhat influences the way the conflict is handled, and the way 
conflict is handled influences future conflict. In the current study the reciprocal nature of these processes could not be examined. And so future research that captures the sequencing of these events would make a significant contribution to our understanding of how the dynamics of group interaction influence and are influenced by the behavior of the group.

A final limitation was the measurement of conflict handling. At the interpersonal level, conflict behavior has been primarily viewed as a conglomeration of the five basic components (van de Vliert et al., 1995). This study generalized this conceptualization of conflict handling to the work group unit of analysis, and employed a widely used and previously validated instrument (Rahim, 1983a). While there were advantages to using this measure, other types of measures might add new insight into the behaviors of group members in response to conflict. For example, by using observational methods researchers could examine the adequacy of the measure as it applies to work groups, and also determine if there are any differences between individual and group conflict handling not captured through the current survey. Nonetheless, this area of research has many questions, and choosing an initial research tool was necessary although not unflawed.

\section{Future Research Directions}

Several avenues for future research seem to follow from this study. The first, as mentioned above, is to replicate this study using alternate ways of measuring conflict handling behaviors that could potentially shed more light on what groups are actually doing between the emergence of a conflict and the relevant outcomes. Additionally, it would be valuable to explore these relationships over time to see how conflict handling at 
one point in the group's life cycle affects the functioning and development of the group in the future.

Qualitative study of work groups by Jehn (1997) identified a third dimension or type of conflict, process conflict, whose effective handling behaviors have yet to be explored. Future research should examine the role of all three types of conflict. Open questions remain concerning the influence of each type of conflict on the development of the other types. Work by Smith (1989) describes the process by which organizational conflict is often rooted in one location yet manifests itself in another. To more fully understand intragroup conflict, research is needed that examines how the three types of conflict move, (e.g. do task conflicts lead to process conflicts?), and what handling behaviors trigger this conflict transformation. Answers to questions like this have eluded much of our research on conflict (Wall \& Callister, 1985) and have the potential to make great leaps in our understanding of core conflict processes.

\section{Conclusions}

Intragroup conflict can have either positive or negative effects on the performance and satisfaction of work groups. The goal of this study was to explore how group conflict management activities effect the productivity or deleteriousness of the conflict faced by small groups. Research such as this that focuses on the underlying variables and processes of groups that determine the effects of their disputes is limited yet essential to a more complete understanding of the nature of conflict. Here, examining the role of different types of conflict management behaviors on the effects of conflict is one step towards this aim of better understanding how conflict can be effectively managed and fostered in order to maximize work group effectiveness. 
Table 1

Individual-Level Variable Means, Standard Deviations, and Coefficient Alpha

Reliabilities $(\mathrm{N}=391)$.

Variable Mean S.D. $\quad \alpha$

Conflict Types

1. Task Conflict

1.82

.70

.84

2. Relationship Conflict

1.77

.81

.78

Task Conflict Handling Behaviors

1. Avoiding

2.96

.83

.75

2. Accommodating

3.68

.72

.80

3. Competing

2.55

.88

.76

4. Collaborating

4.02

.78

.87

5. Compromising

3.60

.85

.76

Relationship Conflict Handling Behaviors

1. Avoiding

3.17

.95

.84

2. Accommodating

3.68

.76

.81

3. Competing

2.57

.95

.81

4. Collaborating

3.99

.80

.88

5. Compromising

3.59

.88

.79

Criterion

1. Group Member Satisfaction

3.96

1.01

.90

Note. All variables ranged from 1 to 5 . 


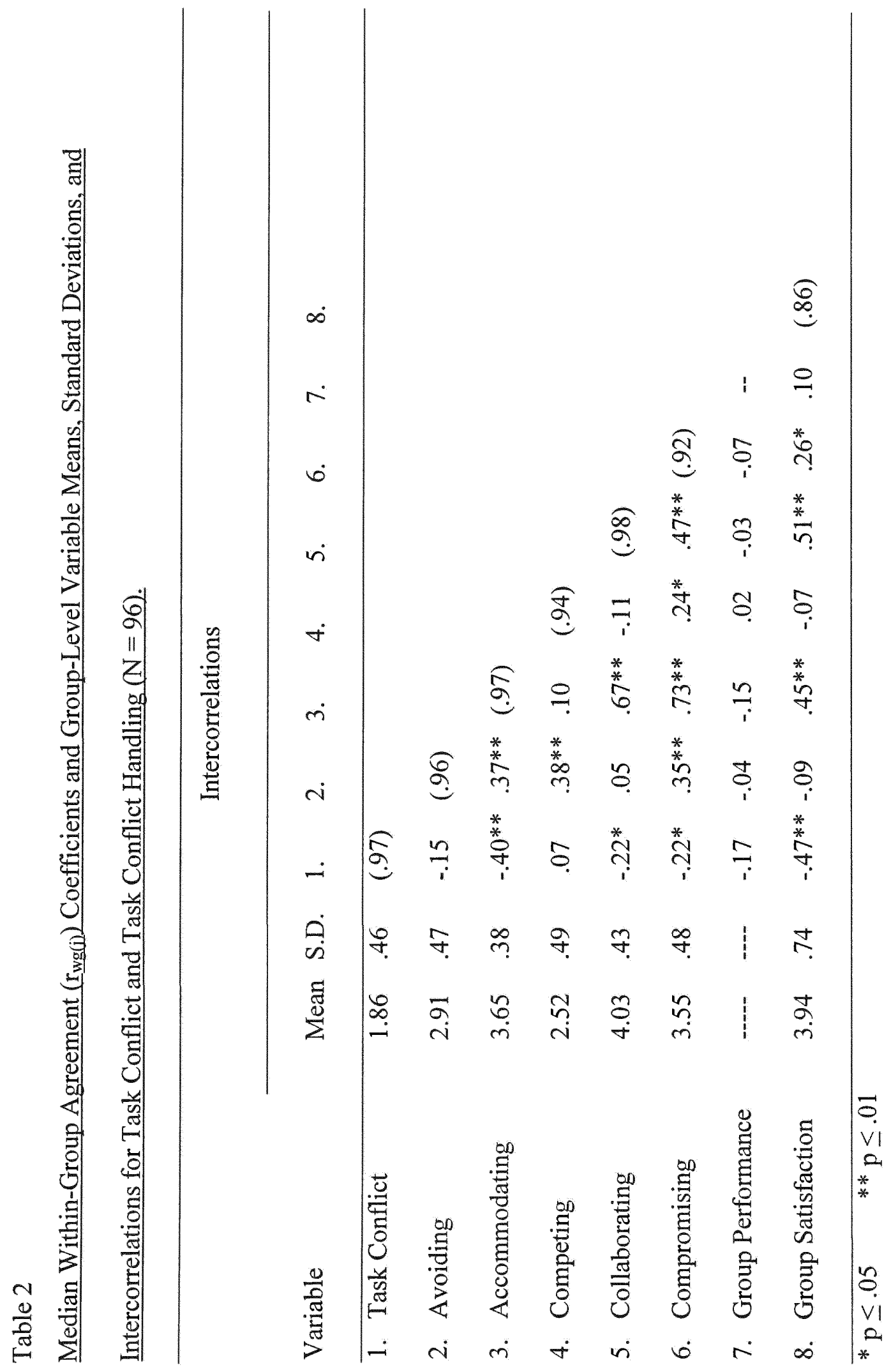




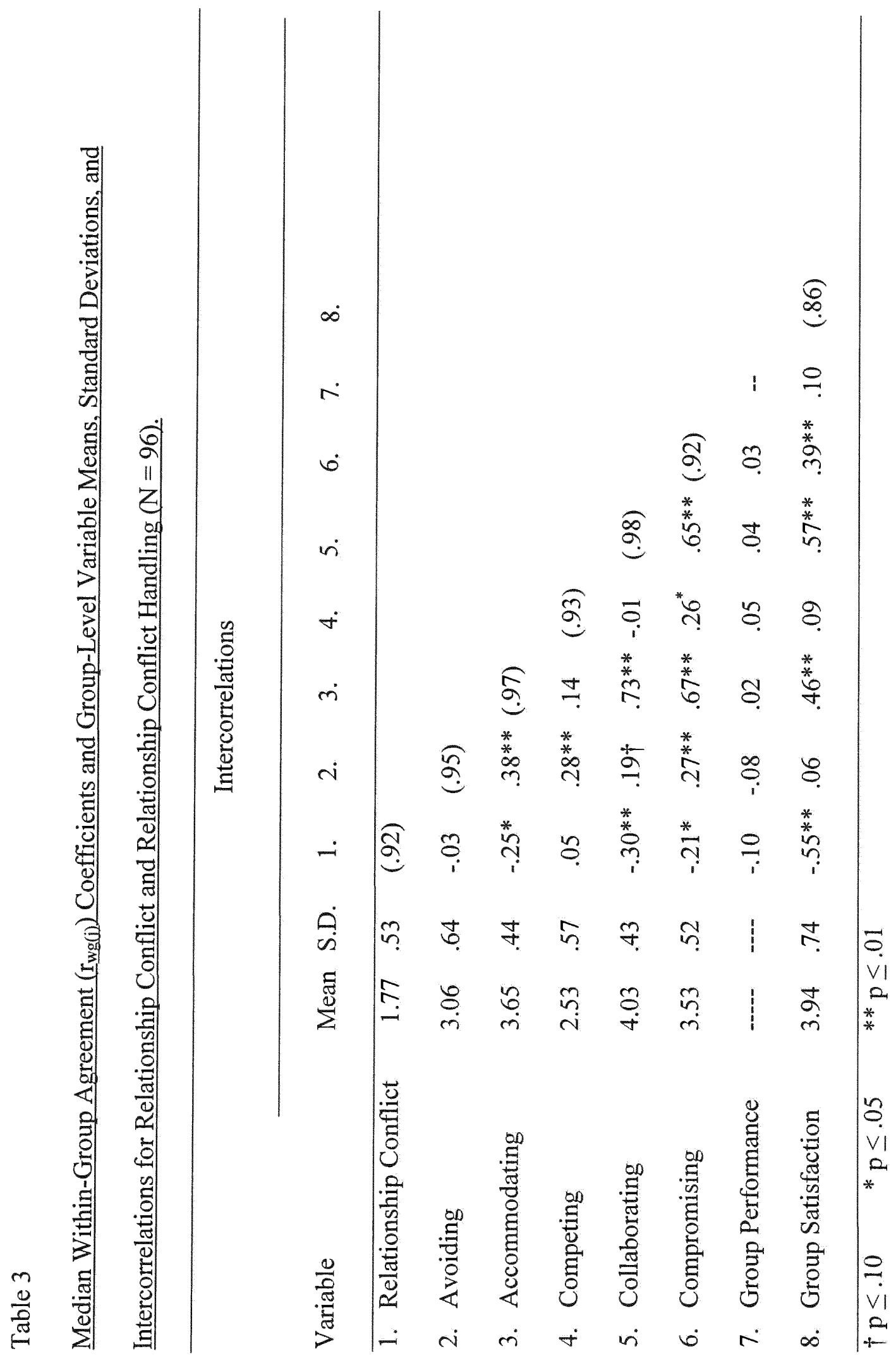




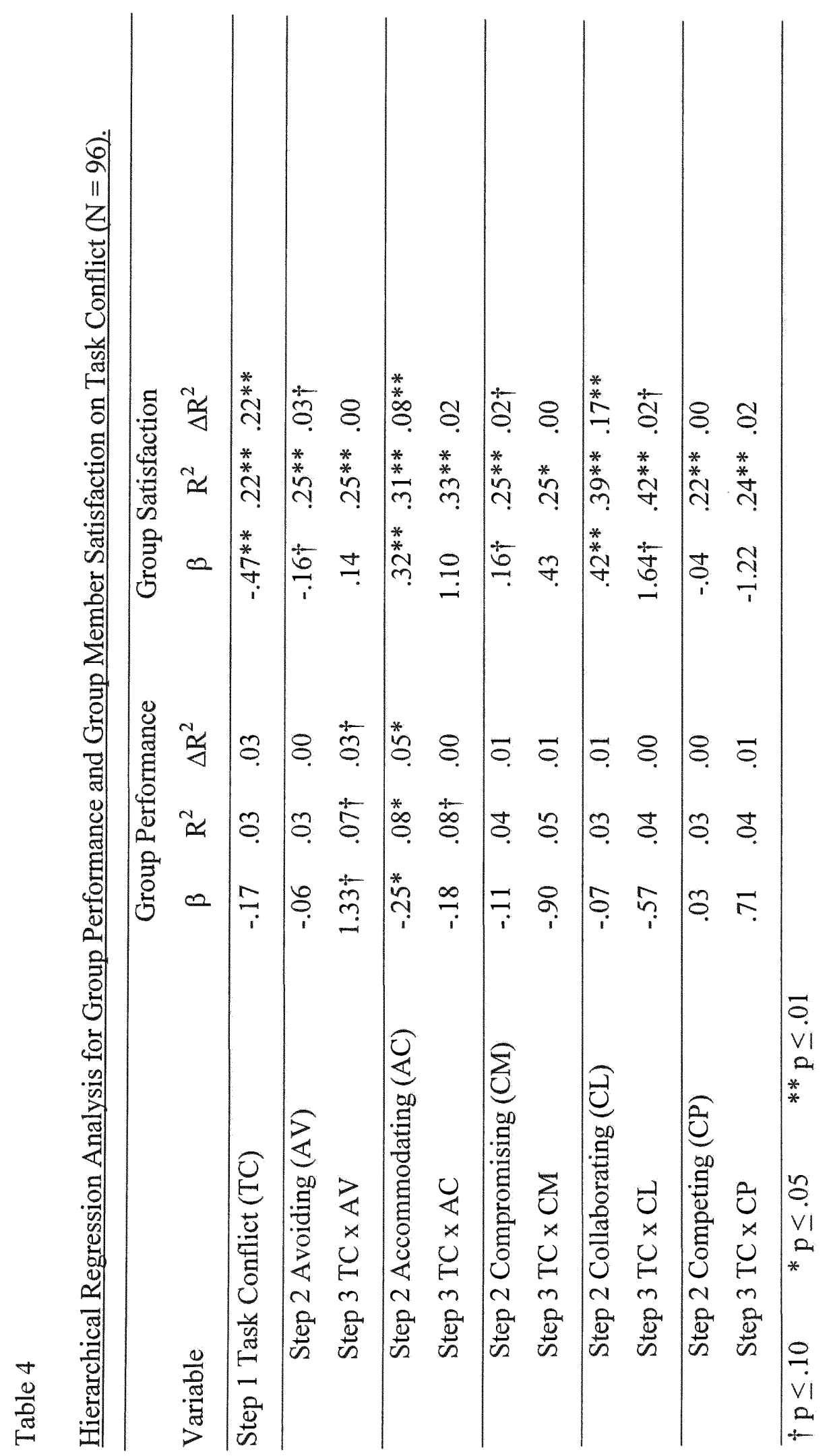




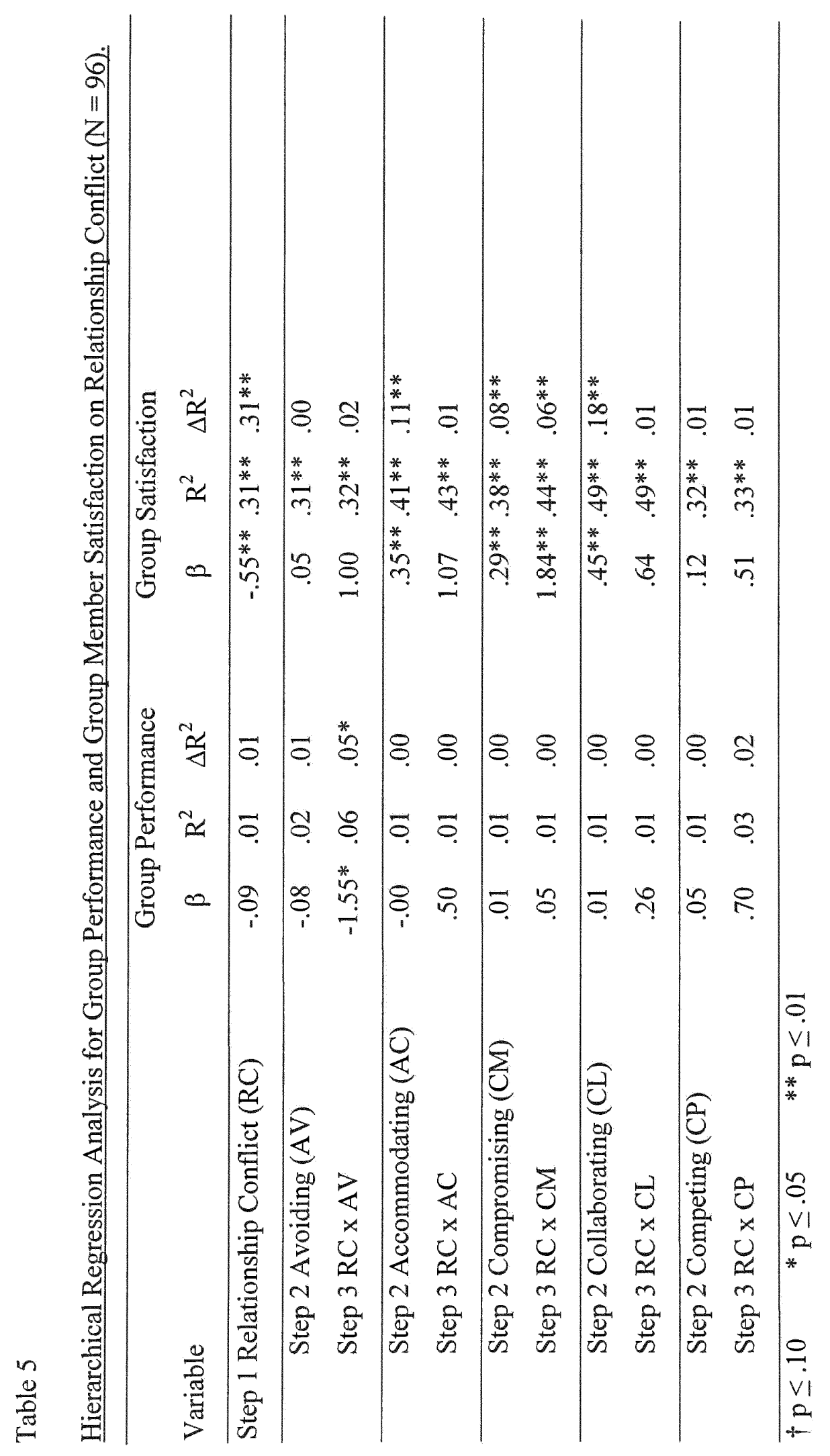


Table 6

Individual-Level Variable Means, Standard Deviations, and Coefficient Alpha Reliabilities $(\mathrm{N}=271)$.

\begin{tabular}{llll}
\hline Variable & Mean & S.D. & $\alpha$
\end{tabular}

Conflict Types

1. Task Conflict

1.79

.61

.80

2. Relationship Conflict

1.69

.72

.71

Task Conflict Handling Behaviors

1. Avoiding

3.00

.83

.75

2. Accommodating

3.69

.71

.79

3. Competing

2.52

.91

.80

4. Collaborating

4.08

.74

.84

5. Compromising

3.59

.87 .74

Relationship Conflict Handling Behaviors

1. Avoiding

3.22

.97

.83

2. Accommodating

3.70

.71

.79

3. Competing

2.52

.97

.82

4. Collaborating

4.05

.75

.86

5. Compromising

3.53

.91

.78

Criterion

1. Group Satisfaction

3.92

.98

.90

Note. All variables ranged from 1 to 5 . 


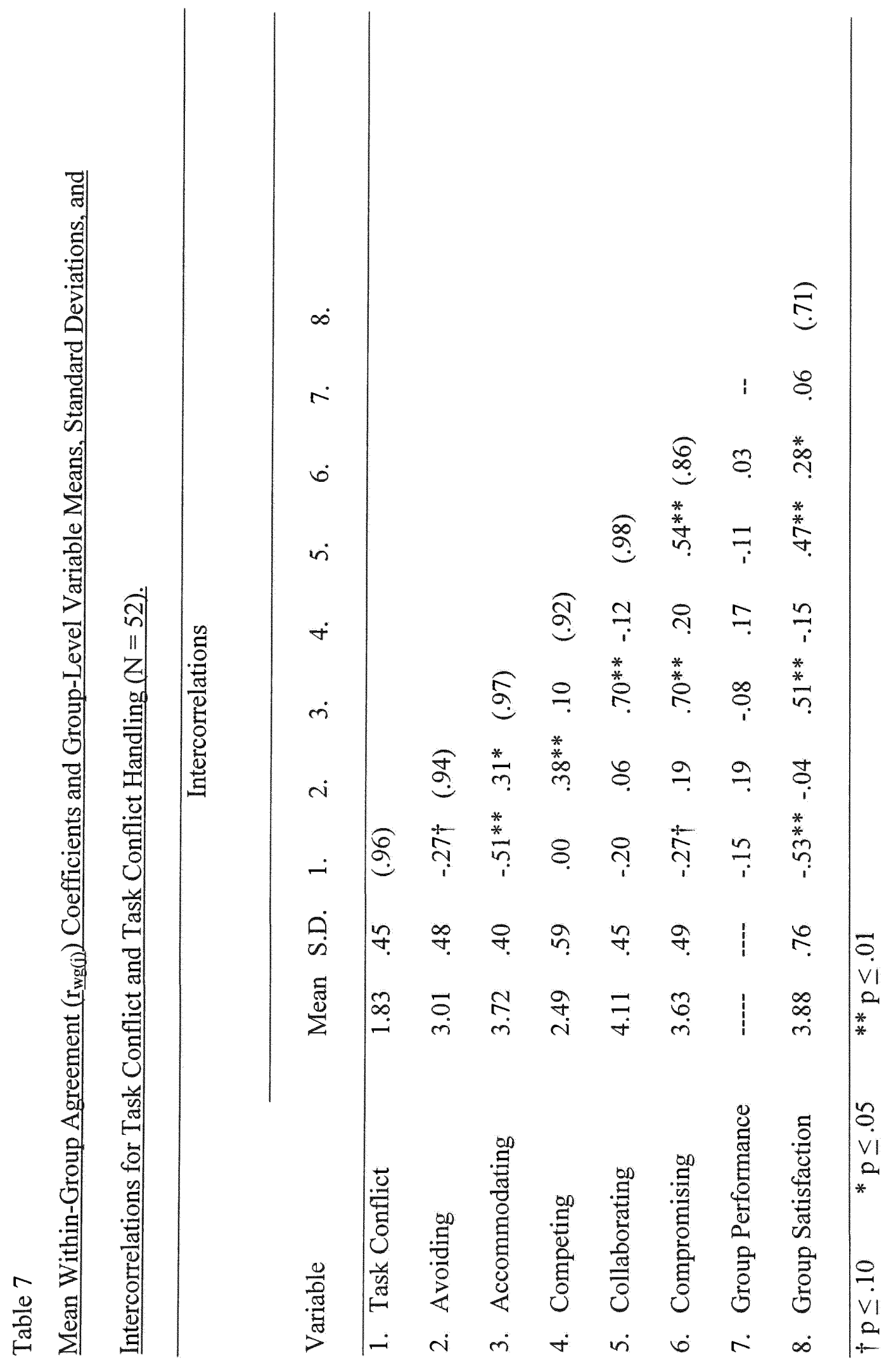




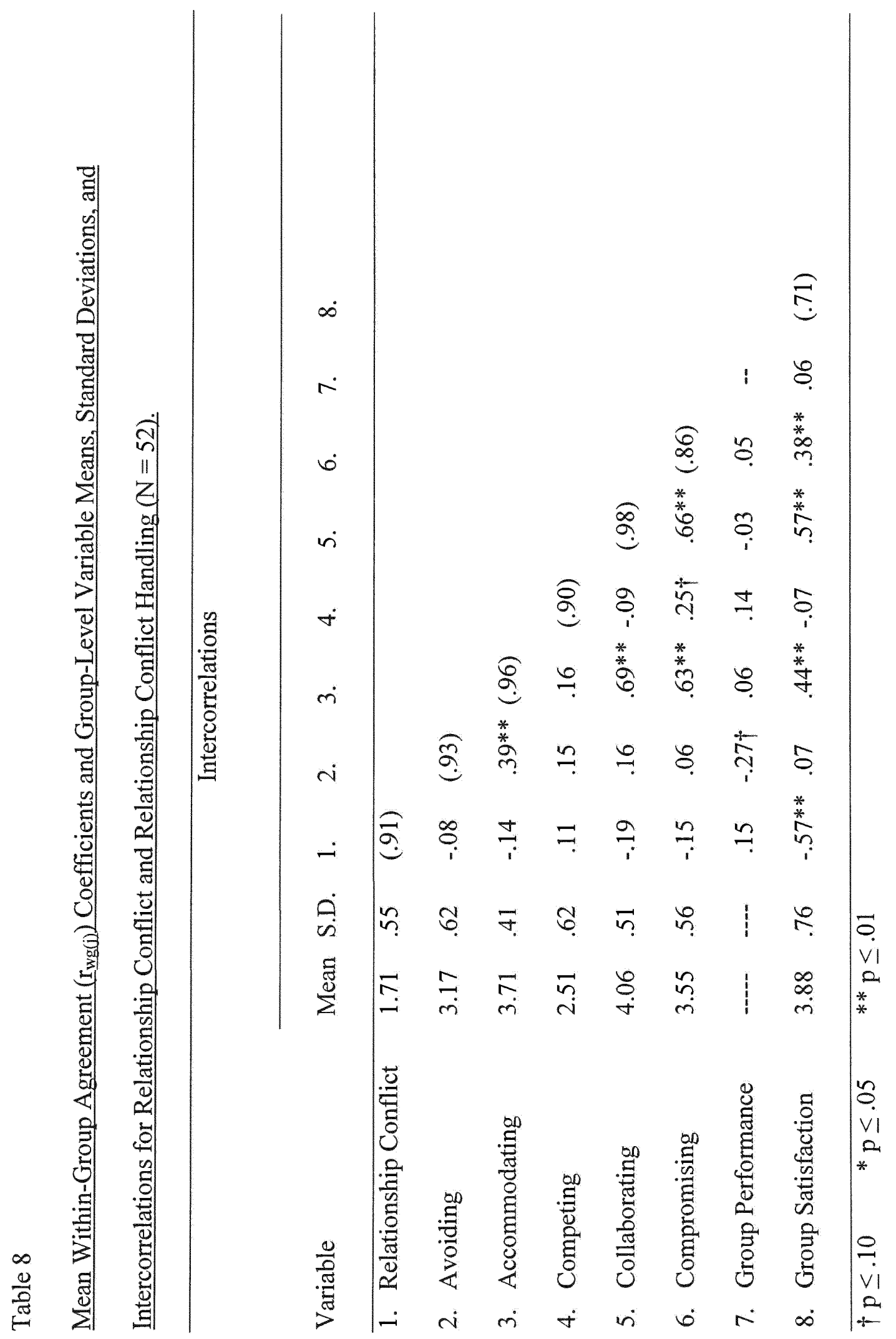




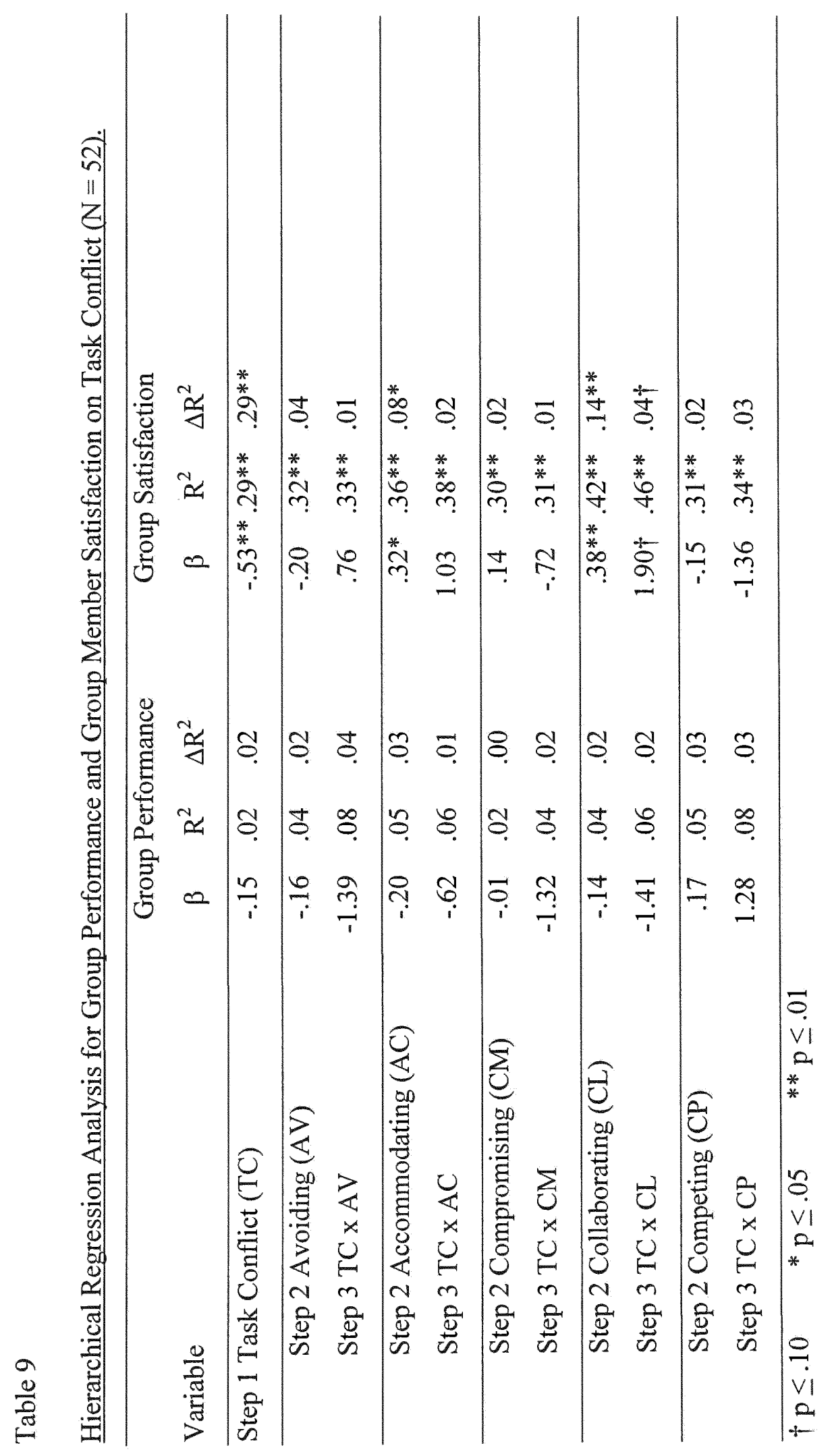




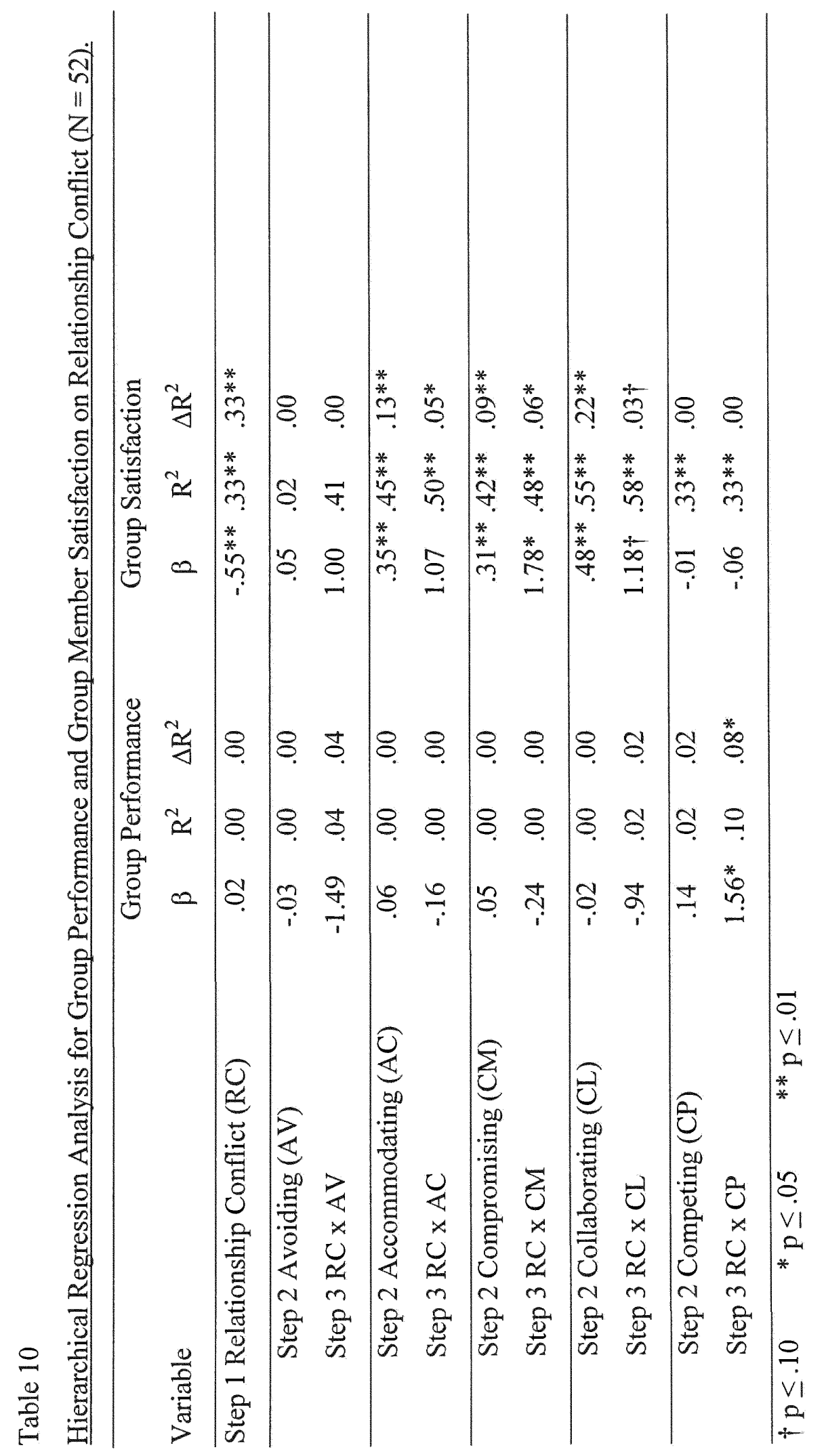




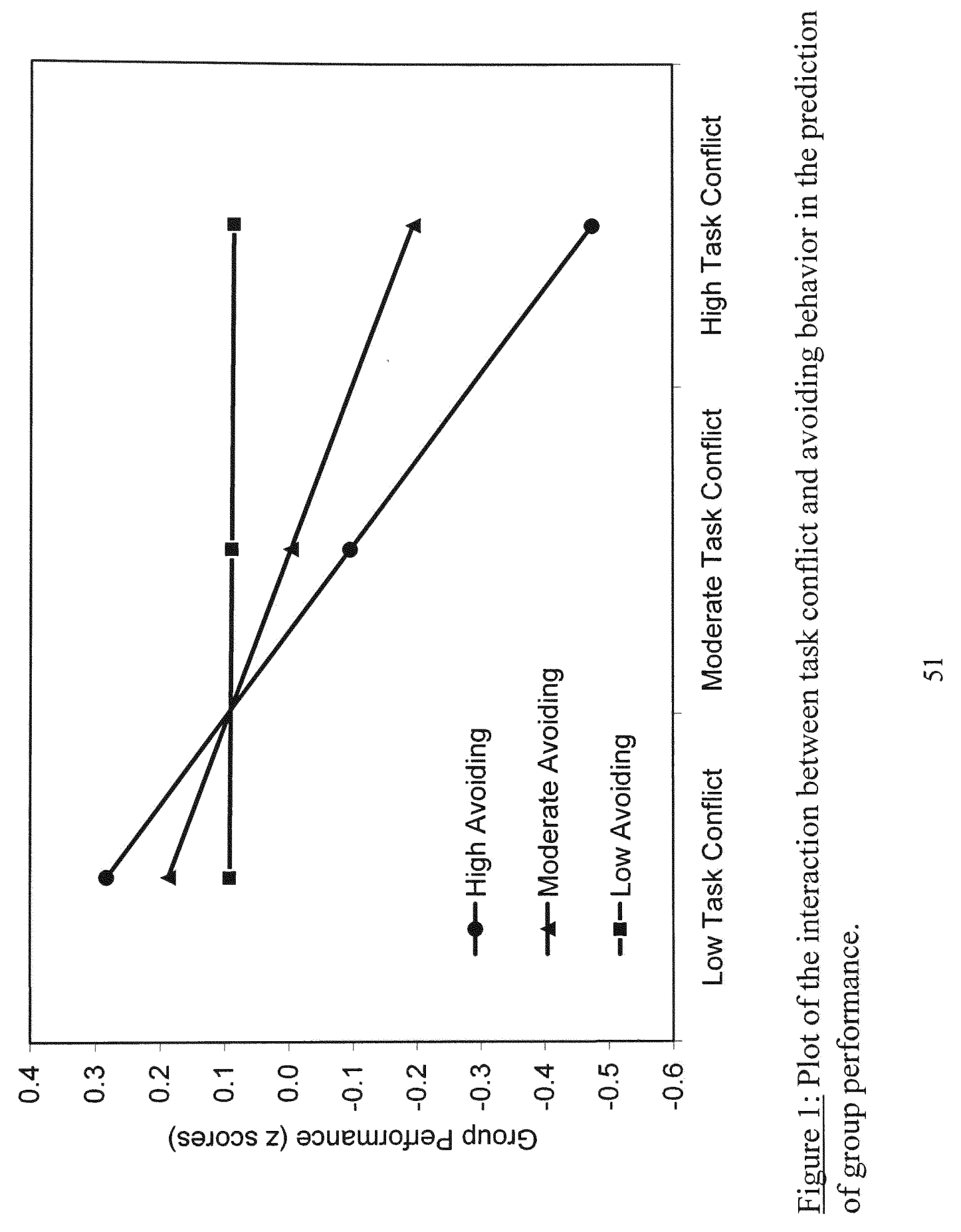




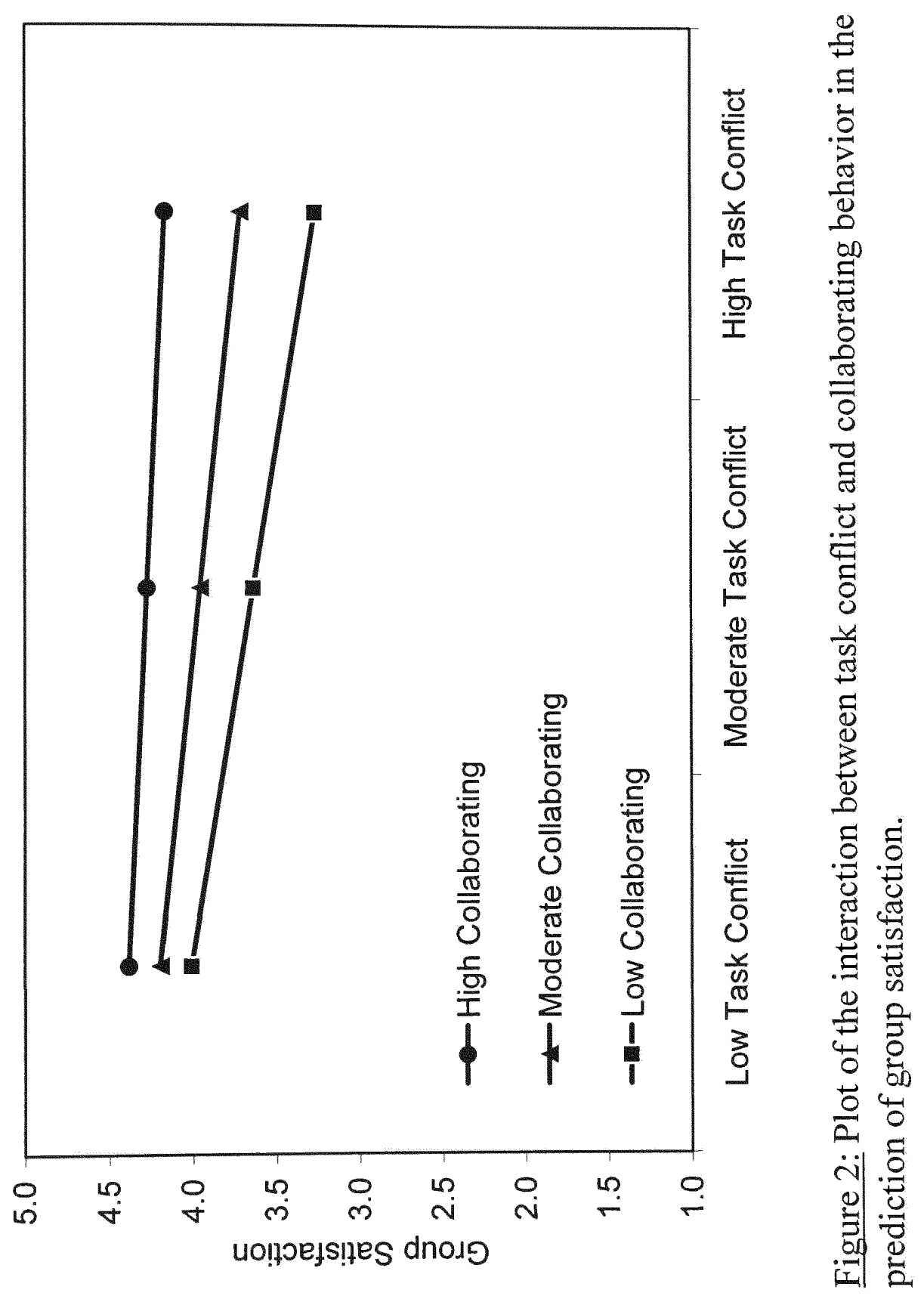




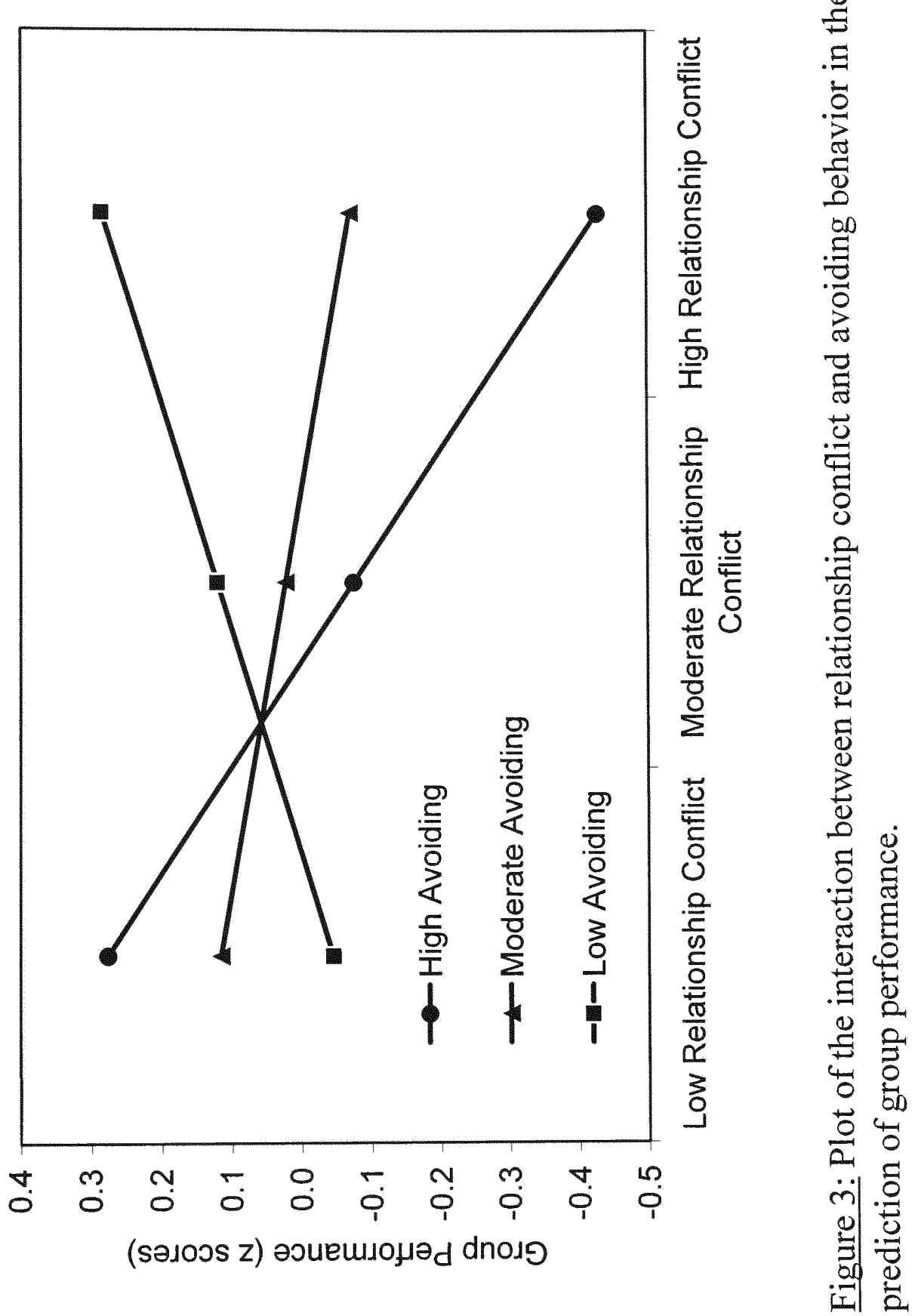




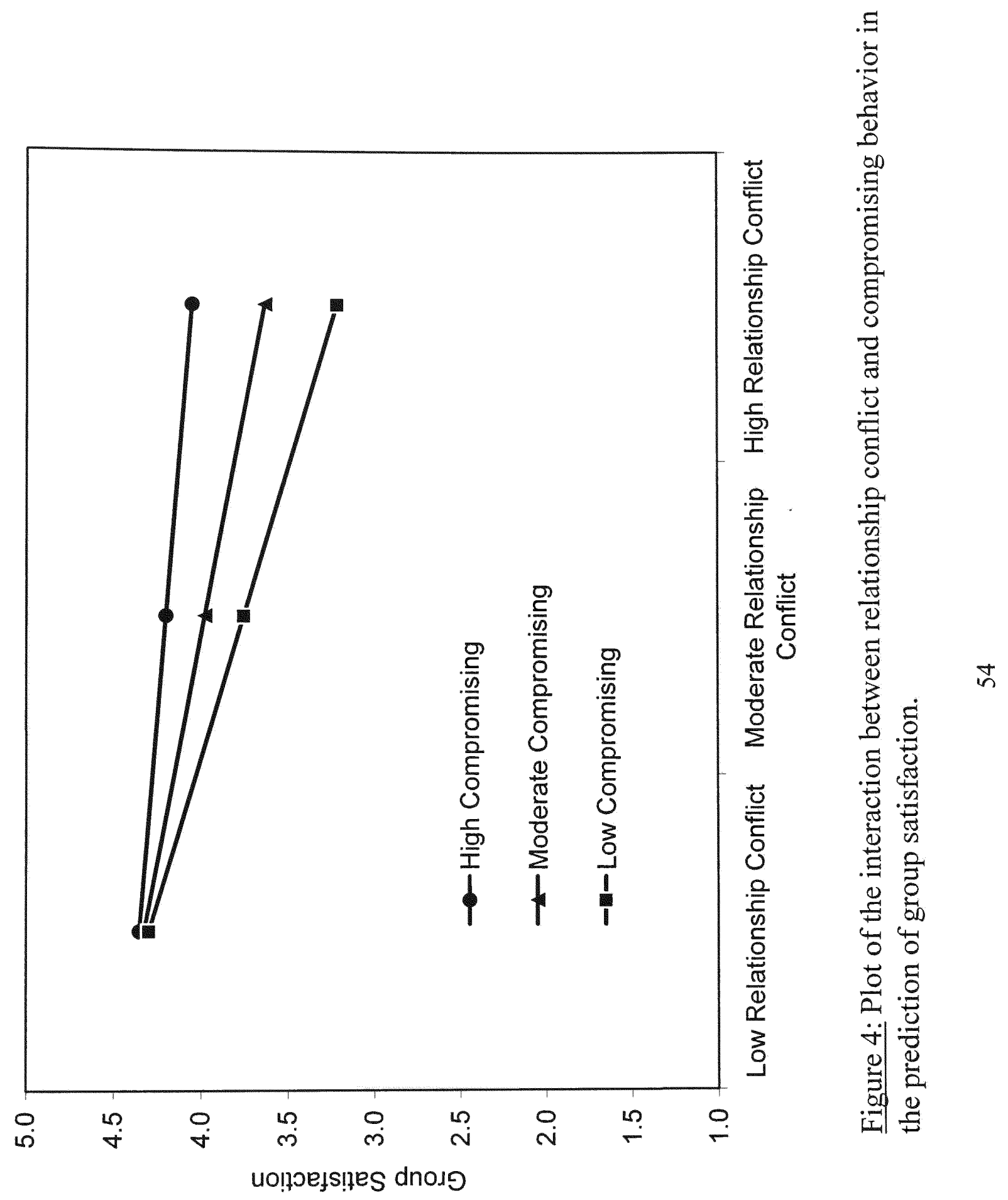




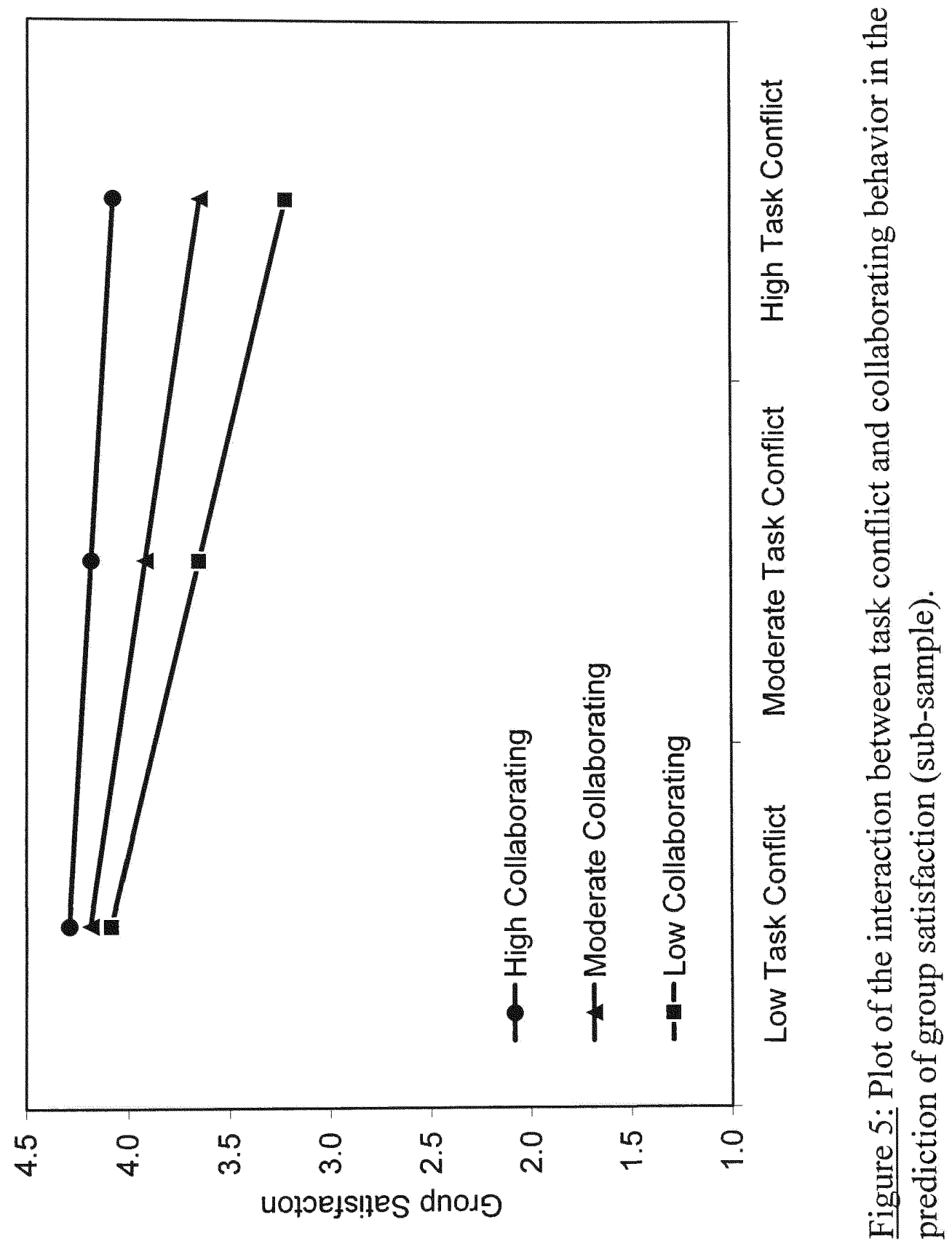




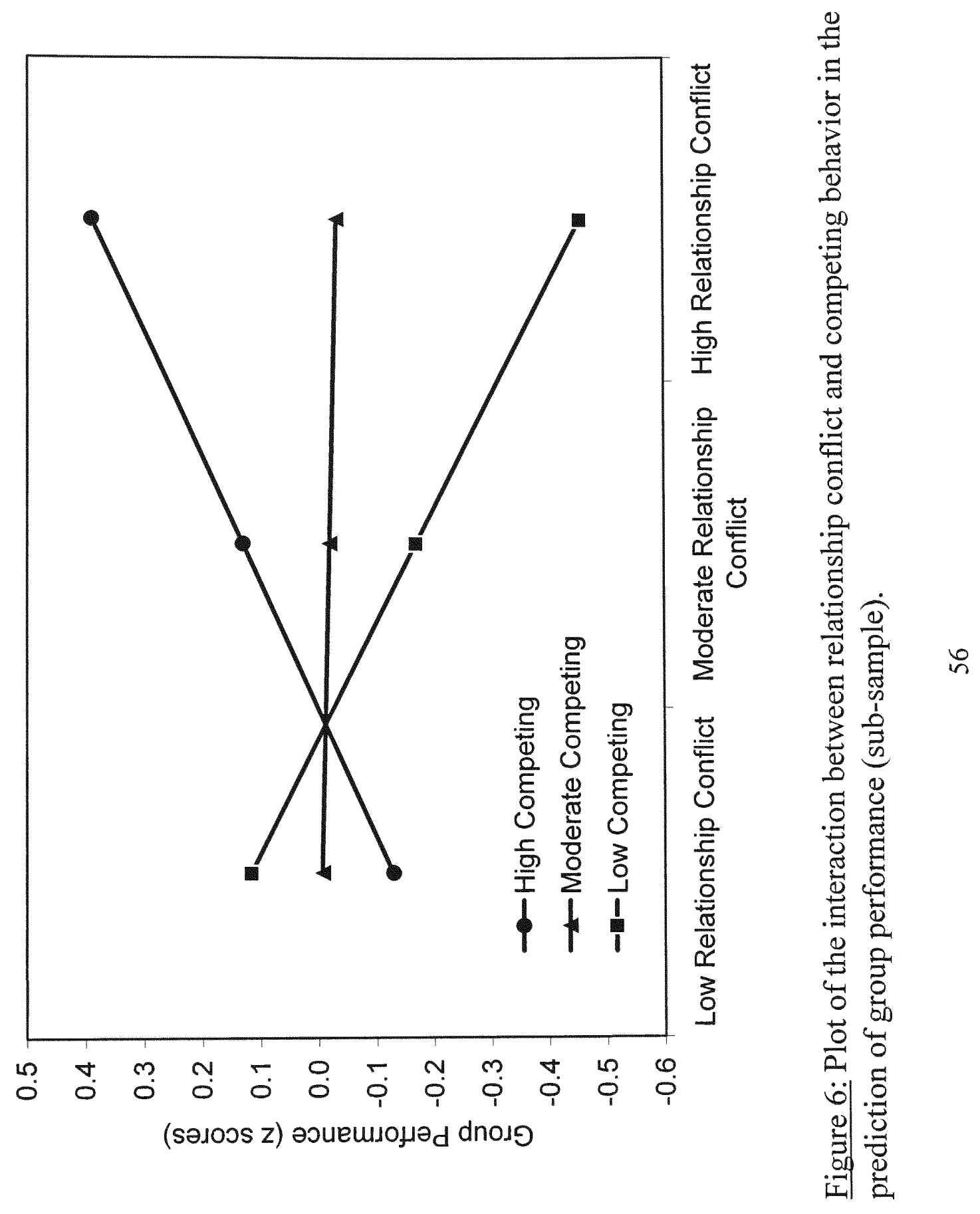




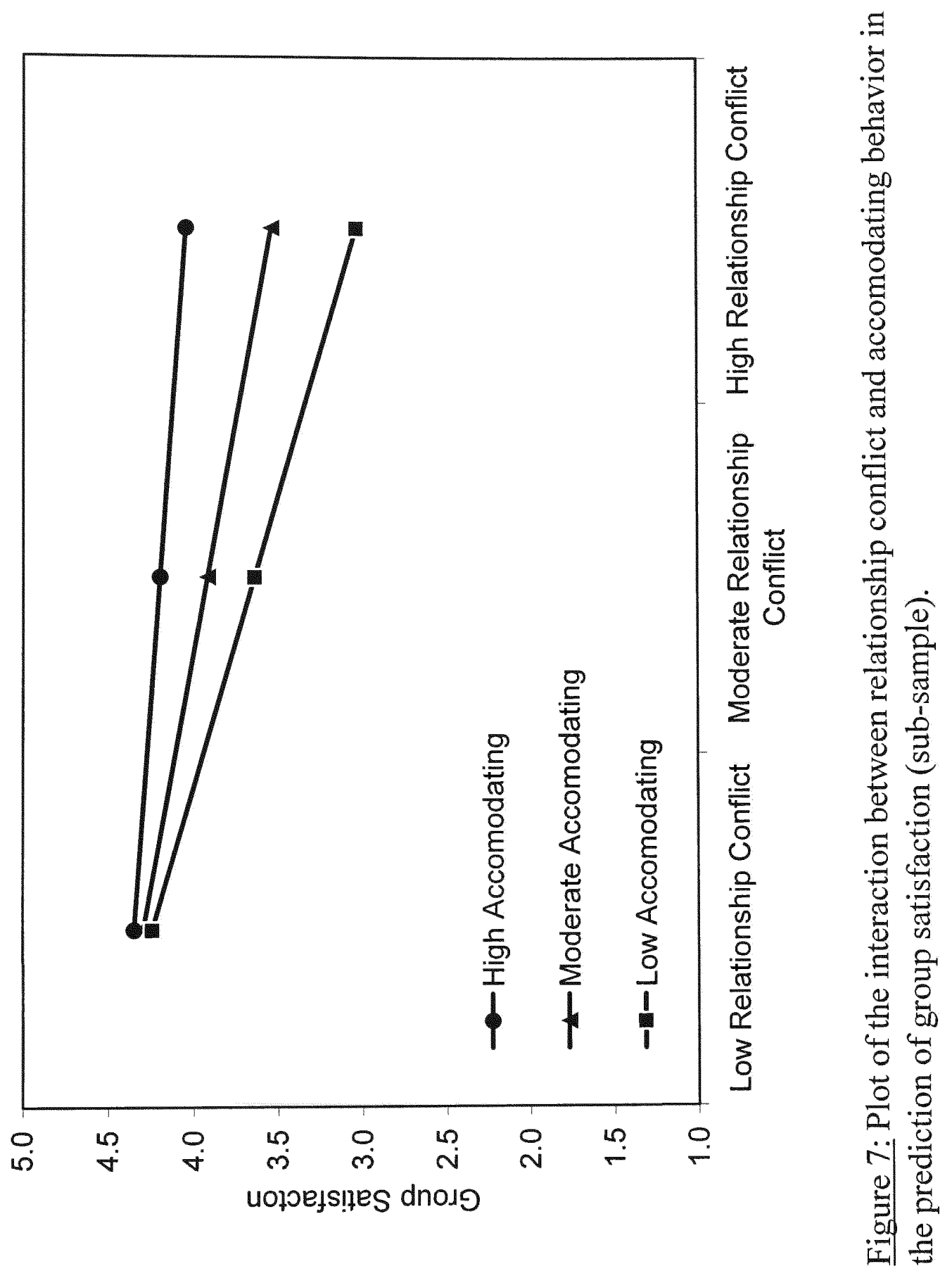




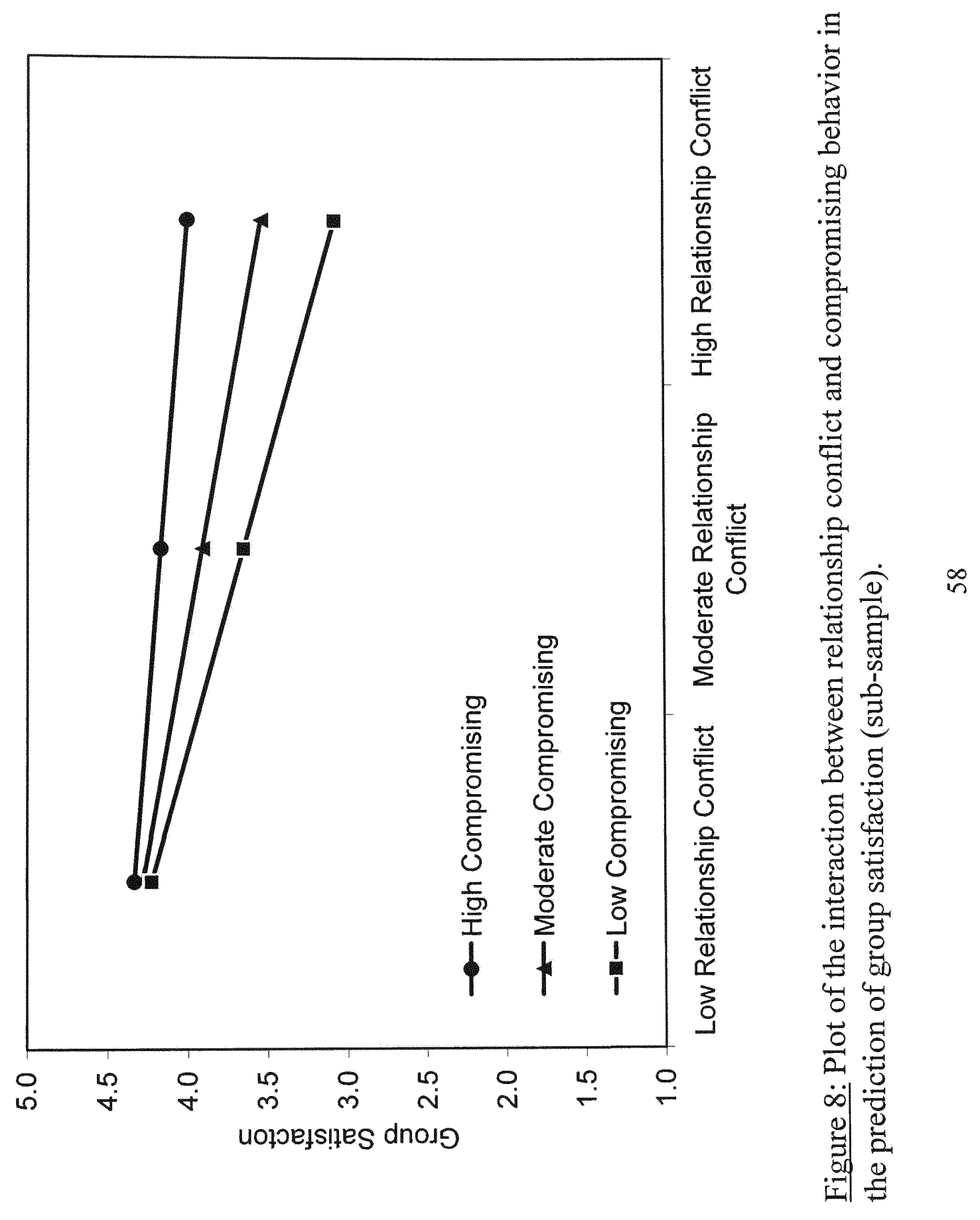




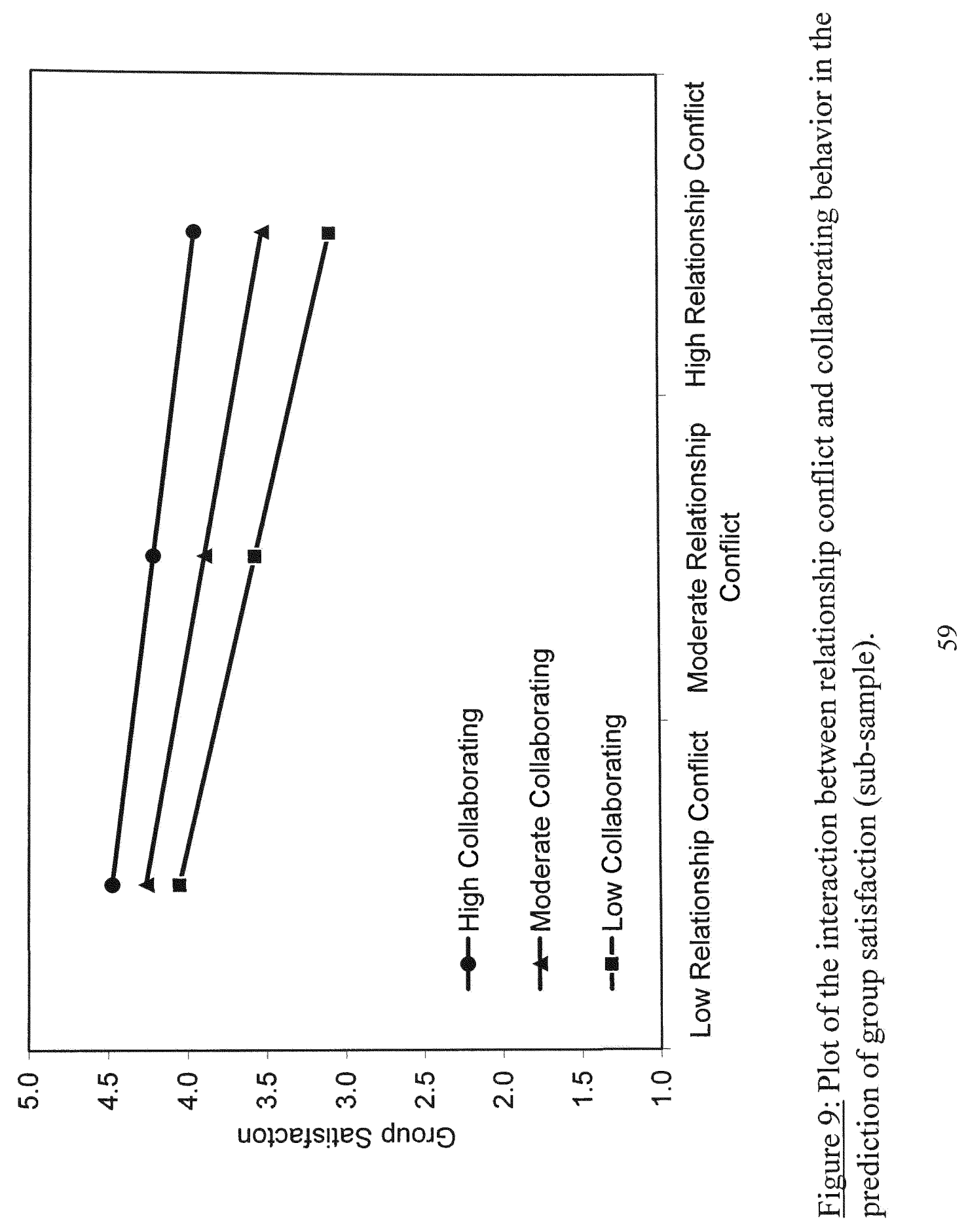


Alter, C. (1990). An exploratory study of conflict and coordination in interorganizational service delivery systems. Academy of Management Journal, 33, 478502.

Amason, A. C. (1996). Distinguishing the effects of functional and dysfunctional conflict on strategic decision making: Resolving a paradox for top management teams. Academy of Management Journal, 39, 123-148.

Amason, A. C. \& Sapienza, H. J. (1997). The effects of top management team size and interaction norms on cognitive and affective conflict. Journal of Management, $\underline{23}, 495-516$.

Amason, A. C. \& Schweiger, D. M. (1994). Resolving the paradox of conflict, strategic decision making, and organizational performance. The International Journal of Conflict Management, 5, 239-253.

Blake, R. R. \& Mouton, J. S. (1964). The managerial grid. Houston, TX: Gulf.

Brown, L. D. (1983). Managing conflict at organizational interfaces. Reading, MA: Addison-Wesley.

Cohen, J., \& Cohen, P. (1983). Applied multiple regression/correlation analysis for the behavioral sciences (2nd ed). Hillsdale, NJ: Lawrence Erlbaum Associates.

Coser, K. (1956). The Functions of Social Conflict. Glencoe, IL: Free Press.

Cosier, R. A. \& Dalton, D. R. (1990). Positive effects of conflict: A field assessment. The International Journal of Conflict Management, 1, 81-92.

Deutsch, M. (1973). The resolution of conflict. New Haven, CT: Yale University Press.

Guetzhow, H. \& Gyr, J. (1995). Analysis of conflict in decision-making groups. Human Relations, 7, 367-381.

Hackman, J. R. (1983). A normative model of work team effectiveness (Technical Report No. 2). New Haven, CT: Yale University.

James, L. R., Demaree, R. G., \& Wolf, G. (1984). Estimating within-group interrater reliability with and without response bias. Journal of Applied Psychology, 69 , 85-98. 
Jehn, K. A. (1992). The impact of intragroup conflict on effectiveness: A multimethod examination of the benefits and detriments of conflict. Unpublished doctoral dissertation, Northwestern University, Evanston, IL.

Jehn, K. A. (1994). Enhancing effectiveness: An investigation of advantages and disadvantages of value-based intragroup conflict. International Journal of Conflict Management, 5, 223-238.

Jehn, K. A. (1995). A multimethod examination of the benefits and detriments of intragroup conflict. Administrative Science Quarterly, 40, 256-282.

Jehn, K. A. (1997). A qualitative analysis of conflict types and dimensions in organizational groups. Administrative Science Quarterly, 42, 530-557.

Jehn, K. A., Chadwick, C., \& Thatcher, S. M. B. (1997). To agree or not to agree: The effects of value congruence, individual demographic dissimilarity, and conflict on workgroup outcomes. The International Journal of Conflict Management, 8, 287-305.

Kilmann, R. H., \& Thomas, K. W. (1977). Developing a forced-choice measure of conflict-handling behavior: The "MODE" instrument. Educational and Psychological Measurement, 37, 309-325.

Marks, M. A., Mathieu, J. E., \& Zaccaro, S. J. (1999). A temporally-based theory and taxonomy of team processes. Manuscript under review.

McGrath, J. E. (1997). Small group research, that once and future field: An interpretation of the past with an eye to the future. Group Dynamics: Theory, Research, and Practice, 1, 7-27.

Messick, D. \& Mackie, D. (1990/1989). Intergroup relations. Annual Review of Psychology, 40, 45-81.

Pinkley, R. L. (1990). Dimensions of conflict frame: Disputant interpretations of conflict. Journal of Applied Psychology, 33, 117-126.

Pondy, L. R. (1967). Organizational conflict: Concepts and models. Administrative Science Quarterly, 12, 296-320.

Priem, R. L., Harrison, D. A., \& Muir, N. K. (1995). Structured conflict and consensus outcomes in group decision making. Journal of Management, 21, 691-710.

Priem, R. L. \& Price, K. H. (1991). Process and outcome expectations for the dialectical inquiry, devil's advocacy, and consensus techniques of strategic decision making. Group and Organization Studies, 16, 206-225. 
Pruitt, D. G. \& Rubin, J. Z. (1986). Social conflict: Escalation, stalemate and settlement. New York, NY: Random House.

Rahim, M. A. (1983a). A measure of styles of handling interpersonal. Academy of Management Journal, 26, 368-376.

Rahim, M. A. (1983b). Rahim organizational conflict inventories. Palo Alto, CA: Consulting Psychologists Press.

Schweiger, D. M., Sandberg, W. R., \& Ragan, J. W. (1986). Group approaches for improving strategic decision making: A comparative analysis of dialectical inquiry, devil's advocacy and consensus approaches to strategic decision making. Academy of Management Journal, 29, 51-71.

Schweiger, D. M., Sandberg, W. R., \& Rechner, P. L. (1989). Experimental effects of dialectical inquiry, devil's advocacy, and consensus approaches to strategic decision making. Academy of Management Journal, 32, 745-772.

Shah, P. P., \& Jehn, K. A. (1993). Do friends perform better than acquaintances? The interaction of friendship, conflict, and task. Group Decision and Negotiation, 2, 149165 .

Smith, K. (1989). The movement of conflict in organizations: The joint dynamics of splitting and triangulation. Administrative Science Quarterly, 34, 1-20.

Sternberg, R. J. \& Dobson, D. M. (1987). Resolving interpersonal conflicts: An analysis of stylistic consistency. Journal of Personality and Social Psychology, 52, 794812.

Thomas, K. W. (1976). Conflict and conflict management. In M. D. Dunnette (Ed.), Handbook of Industrial and Organizational Psychology (pp. 889-935). Chicago: Rand-McNally.

van de Vliert, E. (1990). Sternberg's styles of handling interpersonal conflict: A theory-based reanalysis. The International Journal of Conflict Management, 1, 69-80.

van de Vliert, E. \& Kabanoff, B. (1990). Toward theory-based measures of conflict management. Academy of Management Journal, 33, 199-209.

van de Vliert, E., Euwema, M. C., Huismans, S. E. (1995). Managing conflict with a subordinate or a superior: Effectiveness of conglomerated behavior. Journal of Applied Psychology, 80, 271-281. 
van de Vliert, E. \& Euwema, M. C. (1994). Agreeableness and activeness as components of conflict behaviors. Journal of Personality and Social Psychology, 66, 674-687.

Wall, J. A. \& Callister, R. R. (1995). Conflict and its management. Journal of Management, 21, 515-558.

Watson, W. E., Kumar, K., \& Michaelsen, L. K. (1993). Cultural diversity's impact on interaction process and performance: Comparing homogeneous and diverse task groups. Academy of Management Journal, 36, 590-602. 
Appendix A

Survey Instrument

Group ID

\section{Work Group Survey}

\section{Part 1: Background Information}

1. Age: years (on your last birthday).

2. What is your gender? (circle one) MALE FEMALE

3. What year are you?
A. Freshman
B. Sophomore
C. Junior
D. Senior
E. Graduate

4. Have you ever held a full-time job? If so, for how many years?

5. How would you classify your current or most recent job?
A. Supervisory/Managerial
B. Professional
C. Sales
D. Secretarial/Clerical
E. Service (e.g., cook, maintenance)
F. Manual labor (e.g., landscaping, construction)

6. How would you characterize yourself?
A. White (non-Hispanic)
B. Hispanic
C. African American
D. Asian
E. Other:

Part II: Evaluate the following statements about your work group.

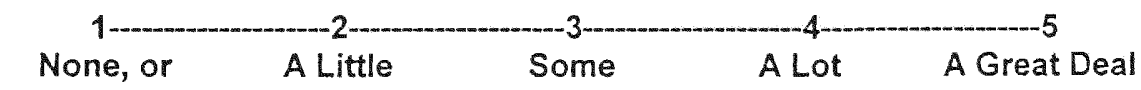
Hardly Any

1. How much interpersonal friction has there been in your work group?

2. How much have personality clashes been evident in your work group?

3. How much emotional conflict has there been in your work group?

4. How much difference of opinion regarding the task(s) has there been in your work group?

5. How much disagreement has there been in your group about your project?

6. How much disagreement has there been about the task your group is working on?

7. How much has your group disagreed about ideas regarding your project? 


\section{TASK CONFLICT}

Part III: Task conflict occurs in work groups when there are disagreements over ideas and alternatives related to your group's project. How have the members of your group handled differing opinions, ideas, and alternatives related to your group's task in the past? For these questions, think only about task-related issues that your group has faced.

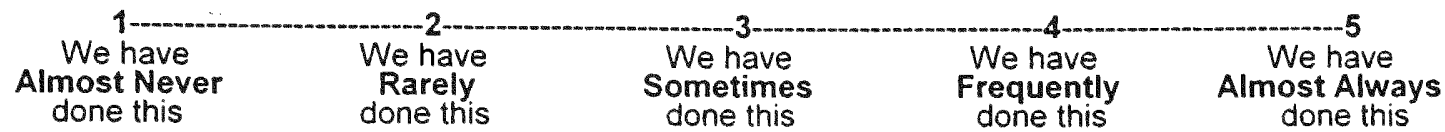

1. We have tried to investigate the issue with each other to find a solution acceptable to all of us.

2. We have tried to satisfy each others' needs.

3. We have attempted to avoid being "put on the spot" and have tried to keep our differing ideas to ourselves.

4. We have tried to integrate each other's ideas to come up with a decision jointly.

5. We have tried to work with each other to find solutions to the issue which satisfy all our expectations.

6. We have avoided open discussion of our differences of opinion.

7. W_ We have tried to find a middle course to resolve the impasse.

8. We have used influence to get our own ideas accepted.

9. We have used authority to make decisions in our own favor.

10. We have accommodated one another's wishes.

11. We have given in to each others' wishes.

12. We have exchanged accurate information with each other to solve the problem together.

13. We have allowed concessions to each other.

14. We have proposed a middle ground for breaking the deadlock.

15. We have negotiated so that a compromise could be reached.

16. We have tried to stay away from disagreement with each other.

17. We have avoided encounters with each other.

18. We have used expertise to make decisions in our own favor.

19. We have gone along with one another's suggestions.

20. We have used "give and take" so that a compromise could be made.

21. We have been firm in pursuing our own side of the issue.

22. We have tried to bring all our task-related concerns out in the open so that the issues could be resolved in the best possible way.

23. We have collaborated with one another to come up with decisions acceptable to all of us.

24. We have tried to satisfy each other's expectations.

25. We have used power to make the final decision.

26. We have tried to keep task-related disagreements to ourselves to avold hard feelings.

27. We have tried to avoid unpleasant exchanges with each other.

28. We have tried to work with each other for a proper understanding of the problem. 


\section{RELATIONSHIP CONFLICT}

Part IV: Relationship conflict occurs in work groups when there are interpersonal differences and disagreements. These disagreements are not directly related to the task assigned to your group. How have the members of your group handled interpersonal differences (e.g. personality problems) in the past? For these questions, think only about relationship issues that your group has faced.

\begin{tabular}{|c|c|c|c|c|}
\hline $\begin{array}{l}\text { We have } \\
\text { Imost Never } \\
\text { done this }\end{array}$ & $\begin{array}{l}\text { We have } \\
\text { Rarely } \\
\text { done this }\end{array}$ & $\begin{array}{l}\text { We have } \\
\text { Sometimes } \\
\text { done this }\end{array}$ & $\begin{array}{l}\text { We have } \\
\text { Frequently } \\
\text { done this }\end{array}$ & $\begin{array}{c}\text { We have } \\
\text { Almost Always } \\
\text { done this }\end{array}$ \\
\hline
\end{tabular}

1. We have tried to investigate the issue with each other to find a solution acceptable to all of us.

2. We have tried to satisfy each others' needs.

3. We have attempted to avoid being "put on the spot" and have tried to keep our interpersonal disagreements to ourselves.

4. We have tried to integrate each other's views to come to a mutual understanding.

5 . We have tried to work with each other to find solutions to the issue which satisfy all our expectations.

6. We have avoided open discussion of our interpersonal differences.

7. We have tried to find a middle course to resolve the impasse.

8. We have used influence to get our own ideas accepted.

9. We have used authority to make decisions in our own favor.

10. We have accommodated one another's wishes.

11. We have given in to each others' wishes.

12. We have exchanged accurate information with each other to solve the problem together.

13. We have allowed concessions to each other.

14. We have proposed a middle ground for breaking the deadlock.

15. We have negotiated so that a compromise could be reached.

16. We have tried to stay away from disagreement with each other.

17. We have avoided encounters with each other.

18. We have used expertise to make decisions in our own favor.

19. We have gone along with one another's suggestions.

20. We have used "give and take" so that a compromise could be made.

21. We have been firm in pursuing our own side of the issue.

22. We have tried to bring all our relationship concerns out in the open so that the issues could be resolved in the best possible way.

23. We have collaborated with one another to come up with decisions acceptable to all of us.

24. We have tried to satisfy each other's expectations.

25. We have used power to make the final decision.

26. We have tried to keep interpersonal disagreements to ourselves to avoid hard feelings.

27 We have tried to avoid unpleasant exchanges with each other.

28. We have tried to work with each other for a proper understanding of the problem. 


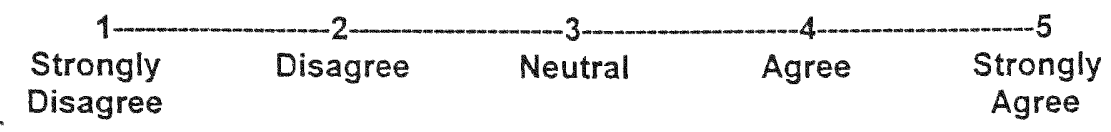

1. Working with this group has been an enjoyable experience.

2. I I would like to work with this group in the future.

3. I I am satisfied with the overall quality of my group's project.

4. I'm generally happy with the results of my group's work.

\section{Part Vl: Group Interaction}

1. Which pattern best describes your group?
A. We met a lot early in the semester.
B. We met throughout the semester, though most of our work was put in early in the semester.
C. We met steadily throughout the semester.
D. We met throughout the semester, though most of our work was put in late in the semester.
E. We met a lot late in the semester.

2. Approximately how many times throughout the semester did you meet with your group to work on your project (outside of class)?
A. $1-2$
B. $3-4$
C. $5-6$
D. $7-8$
E. 9 or more

3. Which of the following best describes how your group's project was completed?
A. Most of the work was done by me.
8. Most of the work was done by me and a subset of the group.
C. The work was equally divided among all members, and completed as a group.
D. The work was equally divided among all members, and completed individually.
E. Most of the work was done by other members.

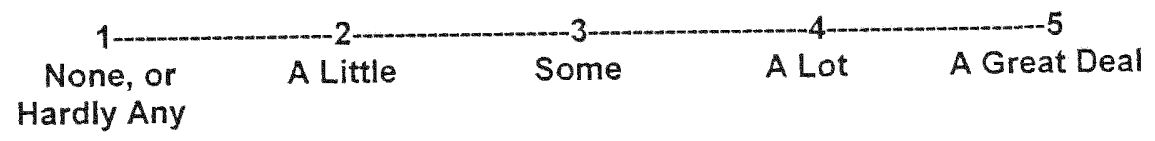

4. How much interaction have you had with your group members?

5. How much time have you spent working with your group members?

6. Did you fill out a similar survey earlier this semester? (circle one) YES NO

Thank you for your participation! 
Appendix B

Survey Items by Variable

Independent Variables

Relationship Conflict

1. How much interpersonal friction has there been in your work group?

2. How much have personality clashes been evident in your work group?

3. How much emotional conflict has there been in your work group?

Task Conflict

1. How much difference of opinion regarding the task(s) has there been in your work group?

2. How much disagreement has there been in your group about your project?

3. How much disagreement has there been about the task your group is working on?

4. How much has your group disagreed about ideas regarding your project?

Moderator Variables

Task Conflict Handling

1. We have tried to investigate the issue with each other to find a solution acceptable to all of us.

2. We have tried to satisfy each others' needs.

3. We have attempted to avoid being "put on the spot" and have tried to keep our differing ideas to ourselves.

4. We have tried to integrate each other's ideas to come up with a decision jointly.

5. We have tried to work with each other to find solutions to the issue which satisfy all our expectations.

6. We have avoided open discussion of our differences of opinion.

7. We have tried to find a middle course to resolve the impasse.

8. We have used influence to get our own ideas accepted.

9. We have used authority to make decisions in our own favor.

10. We have accommodated one another's wishes.

11. We have given in to each others' wishes.

12. We have exchanged accurate information with each other to solve the problem together.

13. We have allowed concessions to each other.

14. We have proposed a middle ground for breaking the deadlock.

15. We have negotiated so that a compromise could be reached.

16. We have tried to stay away from disagreement with each other.

17. We have avoided encounters with each other.

18. We have used expertise to make decisions in our own favor.

19. We have gone along with one another's suggestions.

20. We have used "give and take" so that a compromise could be made.

21. We have been firm in pursuing our own side of the issue.

22. We have tried to bring all our task-related concerns out in the open so that the issues could be resolved in the best possible way.

23. We have collaborated with one another to come up with decisions acceptable to all of us.

24. We have tried to satisfy each other's expectations.

25. We have used power to make the final decision.

26. We have tried to keep task-related disagreements to ourselves to avoid hard feelings.

27. We have tried to avoid unpleasant exchanges with each other.

28. We have tried to work with each other for a proper understanding of the problem. 
Relationship Conflict Handling

1. We have tried to investigate the issue with each other to find a solution acceptable to all of us.

2. We have tried to satisfy each others' needs.

3. We have attempted to avoid being "put on the spot" and have tried to keep our interpersonal disagreements to ourselves.

4. We have tried to integrate each other's views to come to a mutual understanding.

5. We have tried to work with each other to find solutions to the issue which satisfy all our expectations.

6. We have avoided open discussion of our interpersonal differences.

7. We have tried to find a middle course to resolve the impasse.

8. We have used influence to get our own ideas accepted.

9. We have used authority to make decisions in our own favor.

10. We have accommodated one another's wishes.

11. We have given in to each others' wishes.

12. We have exchanged accurate information with each other to solve the problem together.

13. We have allowed concessions to each other.

14. We have proposed a middle ground for breaking the deadlock.

15. We have negotiated so that a compromise could be reached.

16. We have tried to stay away from disagreement with each other.

17. We have avoided encounters with each other.

18. We have used expertise to make decisions in our own favor.

19. We have gone along with one another's suggestions.

20. We have used "give and take" so that a compromise could be made.

21. We have been firm in pursuing our own side of the issue.

22. We have tried to bring all our relationship concerns out in the open so that the issues could be resolved in the best possible way.

23. We have collaborated with one another to come up with decisions acceptable to all of us.

24. We have tried to satisfy each other's expectations.

25. We have used power to make the final decision.

26. We have tried to keep interpersonal disagreements to ourselves to avoid hard feelings.

27. We have tried to avoid unpleasant exchanges with each other.

28. We have tried to work with each other for a proper understanding of the problem.

Dependent Variable

Group Satisfaction

1. Working with this group has been an enjoyable experience.

2. I would like to work with this group in the future. 